JSTP

31,3

\section{6}

Received 5 June 2020

Revised 13 September 2020

18 November 2020

7 January 2021

Accepted 9 January 2021

\title{
Towards a circumplex typology of customer service experience management practices: a dyadic perspective
}

\author{
Yasin Sahhar and Raymond Loohuis \\ Department of Entrepreneurship and Technology Management, \\ University of Twente, Enschede, The Netherlands, and \\ Jörg Henseler \\ Department of Design, Production and Management, University of Twente, \\ Enschede, The Netherlands and \\ NOVA Information Management School, Universidade Nova de Lisboa, \\ Lisbon, Portugal
}

\begin{abstract}
Purpose - The purpose of this study is to identify the practices used by service providers to manage the customer service experience (CSE) across multiple phases of the customer journey in a business-to-business (B2B) setting.

Design/methodology/approach - This study comprises an ethnography that investigates in real time, from a dyadic perspective, and the CSE management practices at two service providers operating in knowledgeintensive service industries over a period of eight months. Analytically, the study concentrates on critical events that occurred in phases of the customer journey that in some way alter CSE, thus making it necessary for service providers to act to keep their customers satisfied.

Findings - The study uncovers four types of service provider practices that vary based on the mode of organization (ad hoc or regular) and the mode of engagement (reactive or proactive) and based on whether they restore or bolster CSE, including the recurrence of these practices in the customer journey. These practices are conveniently presented in a circumplex typology of CSE management across five phases in the customer journey. Research limitations/implications - This paper advances the research in CSE management throughout the customer journey in the B2B context by showing that CSE management is dynamic, recurrent and multifaceted in the sense that it requires different modes of organization and engagement, notably during interaction with customers, in different phases of the customer journey.

Practical implications - The circumplex typology acts as a tool for service providers, helping them to redesign their CSE management practices in ongoing service and dialogical processes to keep their customers more engaged and satisfied.

Originality/value - This paper is the first to infuse a dyadic stance into the ongoing discussion of CSE management practices in B2B, in which studies to date have deployed only provider or customer perspectives. In proposing a microlevel view, the study identifies service providers' CSE management practices in multiple customer journey phases, especially when the situation becomes critical.
\end{abstract}

Keywords Customer service experience management, Customer journey, Dyadic perspective, Ethnographic study, Critical events, B2B knowledge-intensive services

Paper type Research paper

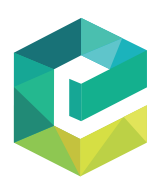

Journal of Service Theory and Practice

Vol. 31 No. 3, 2021

pp. 366-395

Emerald Publishing Limited 2055-6225

DOI 10.1108/JSTP-06-2020-0118
(C) Yasin Sahhar, Raymond Loohuis and Jörg Henseler. Published by Emerald Publishing Limited. This article is published under the Creative Commons Attribution (CC BY 4.0) licence. Anyone may reproduce, distribute, translate and create derivative works of this article (for both commercial and noncommercial purposes), subject to full attribution to the original publication and authors. The full terms of this licence may be seen at http://creativecommons.org/licences/by/4.0/legalcode

The authors thank the anonymous reviewers for their constructive feedback. Moreover, the authors are grateful to MonITor and Train \& Co and their staff members for offering us the opportunity to freely conduct research and engage in their daily practices. 


\section{Introduction}

Understanding the customer experience is key in all service businesses (Helkkula, 2011; Zomerdijk and Voss, 2010). However, service businesses find it challenging to manage a desired customer service experience (CSE) in ongoing service processes and customer journeys. To remedy this situation, businesses have begun to prioritize understanding what their customers experience and when, and they are creating entire departments to investigate, manage and build value promises aimed at providing a "smooth" CSE across the entire customer journey (Siebert et al., 2020). Hence, it comes as no surprise that the concept of CSE has gained increasing traction in marketing practice as well as theory, starting from the idea that service quality and perceptions of service offerings are relevant and can be managed (e.g. Grönroos, 1984; Parasumaran et al., 1988).

Currently, however, managing CSE is highly complex and increasingly challenging (Edelman and Singer, 2015; Rawson et al., 2013). The marketing literature is increasingly finding that CSE is subjective, dynamic and context dependent (e.g. Ellway and Dean, 2016; Helkkula, 2011; Helkkula et al., 2012a; Yakhlef, 2015). In general, such studies show that CSE is a lived and subjective experience and, in a sense, a multifaceted construct (Becker and Jaakkola, 2020) that is difficult to grasp, let alone manage (e.g. Schembri, 2006). CSE is thus susceptible to changes across the multiple phases and touchpoints of the customer journey (Patrício et al., 2011; Zomerdijk and Voss, 2010; Lemon and Verhoef, 2016) and even beyond (Grönroos, 2017).

CSE and customer journeys are not unique to business-to-consumer (B2C) markets but are similarly present in B2B markets and equally relevant (Roy et al., 2019). They both emphasize that the interactions between service providers and customers are "experienced" (Witell et al., 2020). However, in B2B, customer journeys appear to be more complicated for various reasons. First, they entail multiple actors (i.e. decision-making units, DMUs), with each having distinct roles and objectives in various phases of the purchase process (Cortez and Johnston, 2017; Zolkiewski et al., 2017). Second, service offerings are often regarded as more complex and difficult to standardize in nature as opposed to those in B2C markets (Forkmann et al., 2017). Third, service provision requires frequent and different modes of interactions between service providers and customers (Mikolon et al., 2015; Medlin, 2004), depending on the phase in the customer journey (Witell et al., 2020).

Despite its relevance to B2B markets, only a few studies have investigated how the CSE is managed throughout the customer journey. Such studies are largely aimed at providing a conceptual strategic framework for CSE management of customer journeys (Zolkiewski et al., 2017) or practical guidance on how to manage or design customer journeys (De Keyser et al., 2020; McColl-Kennedy et al., 2019; Witell et al., 2020). However, there is still a lack of knowledge about how service providers actually manage CSE in terms of concrete practices in a B2B context throughout the customer journey, an observation that is in line with the service literature (Ostrom et al., 2015; Lemon and Verhoef, 2016; Jain et al., 2017). The studies that have investigated CSE management have adopted either the customer/user perspective (De Keyser et al., 2020; McColl-Kennedy et al., 2019; Zolkiewski et al., 2017) or a service provider perspective (Witell et al., 2020).

Despite the literature's suggestion that service providers as well as customers play an important role in the service delivery process (e.g. Tommasetti et al., 2017; Virlée et al., 2020) and thus in CSE formation, CSE management has been investigated in separate vacuums. This limits our theoretical and practical understanding of how service providers manage CSE in interactions with their customers during the customer journey, which consequently creates a palpable concern for several reasons. Studies from the customers' perspective are incomplete as they capture only those practices that are noticeable by customers. Studies from the firm perspective are incomplete because they do not include customers' reactions to and engagement in practices, thereby leaving the practices' efficacy unexamined. Furthermore, both views
Customer

service

experience

management

367 
JSTP 31,3

368 underexpose CSE's highly interactive nature in which both parties coproduce solutions and play a key role in their formation.

A dyadic perspective of CSE management has the potential to resolve these concerns because it does consider service provider practices in customer-service provider interactions and relationships (Lipkin, 2016) throughout the customer journey. Such an analytical approach permits us to closely investigate the microfoundations of the coproduction (Tommasetti et al., 2017; Virlée et al., 2020) and broader cocreation (Grönroos and Gummerus, 2014) relationship between customers and service providers. Hence, this paper adopts a dyadic perspective on CSE management and is guided by the following research question: "How do B2B service providers in business relationships manage CSE in terms of practices throughout the various phases of the customer journey?".

In line with previous studies in the service research (Grönroos, 2017; Grönroos and Voima, 2013; Holmqvist et al.,2020), we deploy a microlevel perspective to build managerially relevant understandings of CSE in the customer journey from a dyadic perspective. To account for the microlevel, this study employs an ethnographic approach to delve into the dynamics of service providers' CSE management practices in their ongoing efforts to manage CSE in their interactions and relationships with customer throughout the customer journey. Consistent with other contributions in the service literature (e.g. Echeverri and Skålén, 2011; McColl-Kennedy et al., 2015), we adopt a practice lens (Reckwitz, 2002; Schatzki, 1996; Warde, 2005) to examine in greater detail the routinized and nonroutinized actions and modes of engagement of service providers that maintain, balance or otherwise address CSE in their customer relationships.

Empirically, we draw on two in-depth case studies: a B2B training company and an IT consulting firm. Both firms are based in the Netherlands and provide so-called knowledgeintensive business services (e.g. Aarikka-Stenroos and Jaakkola, 2012). One firm provides complex information technology (IT) monitoring solutions, and the other firm provides professional development training in hard and soft skills to firms facing complex organizational change. Due to the knowledge-intensive nature of their services provided, both firms maintain intensive contact with their customers, and frequent interactions are necessary to ensure a desired CSE. Rich- and fine-grained data are gathered through multiple sources during intensive research involving eight months in total. Analytically, we focus on critical events that occur in the relationship between the service provider and customers. The literature has demonstrated that critical events can have a decisive impact on business relationships (Tidström and Hagberg-Andersson, 2012), causing the parties to act and, as such, forming an important source of data (Czarniawska, 2004). In this paper, critical events are defined as occurrences that may positively or negatively alter CSEs and have the potential or the actual ability to create adverse outcomes for the customer.

This study advances contemporary theory and practice on CSE management in multiple ways. Primarily, it contributes to CSE management throughout the customer journey in the $\mathrm{B} 2 \mathrm{~B}$ literature, which is different from traditional approaches in the service research. It reveals four distinct types of practices - made visible in a circumplex typology - that vary by mode of organization and mode of engagement employed by service providers to either bolster or restore CSE in particular phases of the customer journey. It shows that CSE management is a dynamic and critical act that consists of carefully balancing practices with different "modes of organization" (ad hoc or regular) and "modes of engagement" (reactive or proactive) that reoccur during the customer journey. While the extant literature highlights the importance of reactiveness (also referred to as responsiveness) in service recovery (Parasuraman et al., 1988; Virlée et al., 2020) as a distinct process in customer journeys (Van Vaerenbergh et al., 2019), we show that service providers can also bolster (i.e. boost or [supplementarily] enhance CSE in such a way that it surpasses its regular order) CSE through a proactive mode of engagement consisting of constructively exploring solutions for emerging problems in the customer journey. Reactive engagement typically restores CSE (i.e. stabilizes or repairs CSE and returns 
it to its normal order). In the circumplex typology, we also display the recurrence of the practices, which makes it possible to see at a glance which practices (including their nature) are more commonly conducted in a particular phase of the customer journey. Second, with its analytical focus on critical events and typology of CSE management practices, this study contributes to the effective solutioning literature (e.g. Hakanen and Jaakkola, 2012; Storbacka, 2011) by offering a broader range of service provider practices that help in solving customer problems in ongoing service processes. Third, the current research approach for studying CSE from a dyadic perspective on a microlevel opens up novel ideas to deepen the underinvestigated - domain of CSE management in more general terms and for other contexts. Finally, the findings and especially the circumplex typology offer practitioners support to better understand their responses in managing CSE across multiple phases of the customer journey, a process that indeed appears to be a challenge.

The remainder of this paper begins with a brief overview of how CSE and customer journeys have been conceptualized and investigated in the literature to date, touching on CSE management throughout the customer journey. Next is the method followed by the findings section, which presents the service provider practices in detail and develops toward the circumplex typology for CSE management. The paper concludes with a discussion that covers a discussion, theoretical contributions, managerial implications and avenues for future research.

\section{Status quo}

\subsection{CSE}

The traditional service literature has conceptualized CSE as customers' judgment of services; it is usually captured by perceptions of service quality (Parasuraman et al., 1988; Woodruff, 1997; Grönroos, 1984). More recently, the literature has argued that customers can also perceive value in use and thereby has directed researchers' analytical focus to the usage process rather than to outcomes (e.g. Toivonen et al., 2007; Macdonald et al., 2016). Building on this processual notion and the aspect of value in use, scholars have deepened the meaning of CSE in various ways. In particular, service-dominant logic and service logic highlight the phenomenological nature of CSE during the creation of value in use (Vargo and Lusch, 2008, 2016; Grönroos, 2011; Grönroos and Gummerus, 2014), suggesting that the customer is both an interpreter and contributor (Gummerus, 2013). Such an interpretive approach (Zeithaml et al., 2020) suggests that CSE is highly subjective in the sense that it is contextually and idiosyncratically interpreted and experienced by the customer in service provision processes (Jaakkola et al., 2015; Edvardsson et al., 2005; Helkkula, 2011). The paper adopts this perspective on CSE because it conceives of CSE as something that is subject to change for a variety of reasons before, during and after the actual service provision has occurred (Følstad and Kvale, 2018).

\subsection{Phases and touchpoints in the customer journey}

Service customers do not consume a service at a single point in time but are usually engaged in what we currently understand as a customer journey. The role of customer journeys in mapping and understanding customer engagement processes has largely been addressed in the service management literature (Rawson et al., 2013; Zomerdijk and Voss, 2010; Halvorsrud et al., 2016). Customer journeys include the events and phases, regardless of whether they have been purposively designed, experienced by customers in their communications with service providers including their receipt of service offerings (e.g. Følstad and Kvale, 2018; Lemon and Verhoef, 2016; Patrício et al., 2011). As such, a customer journey refers to the process in which CSE is accumulated and formed throughout phases and across touchpoints. 
JSTP 31,3

In $\mathrm{B} 2 \mathrm{C}$, customer journeys are largely product-, brand-, service- or purchase-focused and conceived of as linear in nature, following distinct, successive phases and touchpoints. Examples of such phases and touchpoints include the prepurchase, purchase and postpurchase phases (Lemon and Verhoef, 2016) and precore, core and postcore service encounters (Voorhees et al., 2017). Others focus on the decision phases in the customer journey, which range from awareness, familiarity, consideration and purchase to, eventually, loyalty (Court et al., 2009); such phases are akin to those employed in communication models in advertising (Lavidge and Steiner, 1961).

Customer journeys in the B2B literature are generally conceived as relational processes (Witell et al., 2020) with a focus on buying processes and buying teams (Webster and Wind, 1972). Phases in such journeys roughly relate to the following sequence: prebid engagement, negotiation/value proposition, implementation and operations, including the various touchpoints (Brady et al., 2005; Tuli et al., 2007; Witell et al., 2020). Although the phases in the customer journey appear to be fixed and irreversible, the literature also indicates that customer journeys can be dynamic and bumpy and consist of many iterations (Lemon and Verhoef, 2016). The paper not only acknowledges this dynamic nature of customer journeys but also understands that service providers in B2B settings develop long-term business relationships with their customers through understanding and delivery of value in use (Eggert et al., 2018) and well-practiced relationship management routines that facilitate a positive CSE in the customer journey. This implies that over time and through recurrent interactions, phases in the customer journey become logically structured and envisioned by both parties and constitute an important part of the relationship structure. For our study, we conceptualize the following phases of the customer journey: (1) trigger and problem analysis, (2) orientation and negotiation, (3) choice and purchase, (4) implementation and usage and (5) evaluation and follow-up. Nevertheless, we leave sufficient room for the dynamics that occur in customer journeys due to critical events, setbacks or surprises that urge both customers and service providers to act and interact (McColl-Kennedy et al., 2019).

\subsection{Managing CSE throughout the customer journey}

A persistent question in the service management literature is how CSE can be managed by service providers. The traditional service literature sheds light on the dimensions of providing service quality, such as technical quality, functional quality and organizational image, to maintain a positive perception of the value of a service offering (Grönroos, 1984). Taking service quality as the core driver of value creation, Parasuraman et al. (1988) stressed the use of instruments to ensure the reliability, empathy and responsiveness of service staff, accompanied by assurance and tangible evidence. While the previous literature has basically concentrated on single service encounters, managing CSE throughout the customer journey is more complicated (Edelman and Singer, 2015; Rawson et al., 2013). CSE may vary across phases and touchpoints as well as during everyday interactions between customers and service providers (Patrício et al., 2011;Zomerdijk and Voss, 2010). A complicating factor is that touchpoints may occur long after a service encounter between a customer and service provider; thus, CSE continues to be shaped independently of the service provider (Grönroos, 2017; Norton and Pine, 2013) (Berry et al., 2002, 2006). Furthermore, CSE can be influenced by customers' mental reflections (Grönroos, 2017) and thus are beyond service providers' control.

Indeed, the B2C literature has shown that in such journeys, service failures can easily occur and require service providers to make efforts to restore CSE (Van Vaerenbergh et al., 2019). Instead of viewing such failures as incidents in the customer journey, Van Vaerenbergh et al. (2019) stressed the importance of service recovery by designating it as a "service recovery journey" with its own phases (prerecovery, recovery and postrecovery) including the need for supportive organizational procedures and service staff behaviors with the intent 
of maintaining customer satisfaction. Others have drawn attention to the importance of IT service and support solutions to help technicians and first-line employees seamlessly engage customers at the right moment and in the correct fashion; such solutions have therefore been described as central to CSE (Rawson et al., 2013). Especially in today's multichannel environment, service providers may benefit from such tools, which create insight into touchpoints from the customer's and provider's perspective and into the management of CSE throughout the entire customer journey to deliver a seamless experience between channels.

In the B2B context, the literature highlights the strategic importance of and advocates the move from an input- and output-based approach toward an outcome-based approach for CSE management in customer journeys (Zolkiewski et al., 2017). McColl-Kennedy et al. (2019) assigned specific dimensions to CSE management with the aim of creating value for customers in the customer journey. These dimensions consist of resources, activities, context, interactions and taking into account the customer's roles, which help manage responses and discrete emotions at touchpoints throughout the customer journey. The same authors introduced the necessity for practitioners to manage their customers' journeys. Examples include taking a customer perspective, identifying root causes, uncovering at-risk segments, capturing customers' emotional and cognitive responses, spotting and preventing decreasing sales and prioritizing actions to improve CSE. Witell et al. (2020) offered a framework with the key challenges that are imperative in CSE management: relationship expectations, actor interaction issues and overcoming temporal challenges. Recently, scholars have added more granularity to CSE management in the customer journey and proposed the nomenclature of "touchpoints, context, qualities" (TCQ) to help the audit, design and innovation of CSE more actionable (De Keyser et al., 2020). This classification, which is inspired by the previous research (e.g. Bolton et al., 2018; Homburg et al., 2017), consists of helpful managerial guidance to streamline touchpoints; understand and recognize contexts; assess delivered qualities and evaluate, benchmark and move to action. Jointly, these contributions are helpful not only in designing and installing intervention points in the customer journey with the aim of managing CSE to a desired state but also for analytical use and theory advancement.

However, some difficulties remain despite the strategies and frameworks offered for effective CSE management throughout the customer journey. To date, studies on CSE management throughout the customer journey in a B2B context have adopted either a service provider (Witell et al., 2020) or customer perspective (De Keyser et al., 2020; McColl-Kennedy et al., 2019; Zolkiewski et al., 2017). We suggest that understanding the practices underlying CSE management requires a dyadic perspective from which we can examine the interactions in the collaborative dialogical processes underlying CSE management (Grönroos and Gummerus, 2014). This includes subprocesses such as coproduction, which are typified by customer participation in the development, realization and more effective and efficient provision of an offering (Tommasetti et al., 2017; Virlée et al., 2020). Furthermore, a dyadic view involves customers' engagement and reactions to service provider practices, which allow a more thorough understanding of the practices' efficacy and CSE management as a whole. A dyadic perspective implies that the interactions between customers and service providers across phases and touchpoints in the customer journey constitute a unit of analysis rather than either customers or service providers independently. Furthermore, given the lack of processual studies of CSE management, we know little about what service providers do in relation to their customers when managing CSE throughout the entire customer journey instead of considering service encounters independently. For instance, which organizational processes do service providers use to respond and manage CSE, and how do they engage with customers? When does the management of CSE become a pressing theme for service providers, and what is the role of changing CSE on behalf of customers and in which phase of the customer journey? In addressing these questions, this paper adopts a practice perspective (Reckwitz, 2002; Schatzki, 1996; Whittington, 2006) to attest to the actions of service providers in ongoing service 
JSTP 31,3 provision processes with their customers. A practice perspective is particularly useful for its focus on the predispositions and routinized or nonroutinized behaviors of service providers to manage CSE, and it is commonly applied to service research with a focus on CSE in valuecreation practices (e.g. Helkkula et al., 2012a; b; Jaakkola et al., 2015; Echeverri and Skålén, 2011; McColl-Kennedy et al., 2015). In summary, this paper takes a dyadic perspective by examining the efforts of service providers to manage the dynamic nature of CSE in phases of the customer journey. How exactly this was accomplished will be discussed in the next section.

\section{Methods}

\subsection{Research design and cases}

The objective of our study is to explore and identify the practices of service providers to manage CSE throughout the various phases of the customer journey. We built on a qualitative case study approach involving intensive ethnographic research. Ethnography is concerned with the subject's first-hand "lived experience" by generating so-called thick descriptions (Geertz, 1994; Van Maanen, 2011; Visconti, 2010). This is in line with scholars' advocating of ethnographic approaches in marketing (e.g. Grönroos and Voima, 2013; Norton and Pine, 2013) and specifically the CSE research (De Keyser et al., 2020; Verleye, 2019; Witell et al., 2020; Zeithaml et al., 2020). We deemed an ethnographic approach to be appropriate because of its potential to provide an in-depth understanding of the characteristics of the practices conducted by service providers to manage CSE in interactions with their customers.

Our data comprise ethnography of two Dutch firms in the B2B sector located in the eastern part of the Netherlands. Both companies are reputable, provide services to customers nationally and have served over 2500 customers operating in B2B markets. For the sake of confidentiality, we refer to these firms as "MonITor" and "Train \& Co". Table 1 gives more insight into the firms' key characteristics and activities. It is important to note that both service providers are directly responsible for fulfilling their value promises and managing

\begin{tabular}{|c|c|c|}
\hline Description & MonITor & Train \& Co \\
\hline Established since & 2004 & 2001 \\
\hline $\begin{array}{l}\text { Type and number } \\
\text { of employees }\end{array}$ & $\begin{array}{l}\text { Approximately } 20 \text { permanent staff } \\
\text { members consisting of a board, account } \\
\text { managers, service experts and support } \\
\text { staff, complemented with freelance } \\
\text { consultants }\end{array}$ & $\begin{array}{l}\text { Approximately } 25 \text { permanent staff } \\
\text { members consisting of a board, mainly of } \\
\text { account managers and a few sales } \\
\text { coordinators, complemented by freelance } \\
\text { trainers }\end{array}$ \\
\hline Core business & $\begin{array}{l}\text { Providing organizations with complex IT } \\
\text { monitoring solutions }\end{array}$ & $\begin{array}{l}\text { Providing professional development } \\
\text { training in hard and soft skills to firms } \\
\text { facing complex organizational change }\end{array}$ \\
\hline \multirow[t]{6}{*}{ Core activities } & $\begin{array}{l}\text { (1) Identifying an organization's } \\
\text { challenges and needs }\end{array}$ & $\begin{array}{l}\text { (1) Identifying an organization's } \\
\text { challenges, needs and ambitions }\end{array}$ \\
\hline & $\begin{array}{l}\text { (2) Creating insight into an } \\
\text { organization's IT systems }\end{array}$ & $\begin{array}{l}\text { (2) Creating insight into an organization's } \\
\text { employees' skills and knowledge }\end{array}$ \\
\hline & Advising organizations on fitting & Organizing trainings \\
\hline & $\begin{array}{l}\text { solutions to organizational challenges } \\
\text { (4) Implementing solution at }\end{array}$ & $\begin{array}{l}\text { (4) Training an organization's employees } \\
\text { in hard and soft skills }\end{array}$ \\
\hline & $\begin{array}{l}\text { organizations through interim work } \\
\text { activities and/or workshops }\end{array}$ & $\begin{array}{l}\text { (5) Advising organizations about } \\
\text { suitable training programs }\end{array}$ \\
\hline & $\begin{array}{l}\text { (5) Coaching and supervising progress at } \\
\text { organizations }\end{array}$ & $\begin{array}{l}\text { (6) Coaching organizations in } \\
\text { safeguarding knowledge and skills }\end{array}$ \\
\hline $\begin{array}{l}\text { Intensity of } \\
\text { customer } \\
\text { interaction }\end{array}$ & $\begin{array}{l}\text { Highly intensive customer interaction over } \\
\text { long periods (more than three - six } \\
\text { months) }\end{array}$ & $\begin{array}{l}\text { Highly intensive customer interaction over } \\
\text { short (a week) and long (more than three - } \\
\text { six months) periods }\end{array}$ \\
\hline
\end{tabular}

\section{customer} eraction interaction
Table 1.

Description of research cases 
CSE. Although freelance trainers and consultants are sometimes engaged, they are trained and educated extensively in line with both service providers' principles. Furthermore, they operate under MonITor's and Train \& Co's name, making it impossible for customers to know that the services are occasionally outsourced.

Similar to the criteria and characterizations of other businesses that provide knowledgeintensive services (Aarikka-Stenroos and Jaakkola, 2012; Bettencourt et al., 2002), MonITor and Train \& Co provide customized services and solutions that aim to contribute to customers' needs and value creation and deliver an excellent CSE. In doing so, both firms develop, create and disseminate knowledge through their services and solutions, requiring intensive customer interaction and problem-solving capabilities (Muller and Zenker, 2001) in the context of the cocreation and coproduction customer-supplier relationship (Bettencourt et al., 2002) throughout the various customer journey phases. Hence, both cases appeared suitable for the goal of this research.

\subsection{Data collection}

When collecting the data, we focused on critical events between customers and service providers. In contrast to data capture techniques such as the critical incident technique (Flanagan, 1954) or similar techniques (Edvardsson and Roos, 2001), in which respondents are explicitly questioned on certain "critical incidents," we focused on critical events as they occurred in the relationship between the case companies and their customers. In line with the previous research (Tidström and Hagberg-Andersson, 2012; Ylimäki, 2014), we selected the critical events ourselves based on the criterion that they forced both parties to act and interact. Critical events are occurrences that initiate change and have a decisive impact on a business dyad because they may positively or negatively alter CSEs (Halinen et al., 1999) and have the potential or actual ability to create adverse outcomes for the customer (Taylor, 1991). Examples of such events are moments in which customers are dissatisfied with the service they receive in relation to the value offering or due to internal issues beyond the service provider's control but somehow affecting the CSE. Furthermore, by choosing the critical events ourselves, we interfere the least with the customer-supplier dyad, which best accommodates our ethnographic immersion.

Sufficient immersion with the study object is key in ethnographic research (Van Maanen, 2011). The lead ethnographer in this study was the first author of this paper. He ensured sufficient immersion from the beginning of the research project by visiting both companies two and a half days per week over a period of eight months. Given this amount of time, he was able to become deeply engaged with the firms' service offerings, journeys, interactions and relationship management practices. Both companies share one office building, which saved considerable travel time.

The data collection palette is multifaceted (see Table 2), which is in line with the idea that the researcher should observe details in different settings and at different times (O'Reilly, 2012). Initially, the first author proactively organized a welcome and question and answer (Q\&A) session that contributed to gaining trust and confidence from the employees. He also organized short, informal acquaintance meetings with individual employees to become familiar with their background and job function. These initial gatherings contributed to the building of rapport. Shortly thereafter, the first author joined representatives such as account managers, directors, consultants and trainers during customer visits. He attended meetings at their customers as well as internal formal and informal encounters, especially during critical events. He conducted in-depth interviews with customers as well as employees of both firms and organized internal workshops to become familiar with the companies' offerings, industries and customer journeys. He joined training sessions and was trusted to become a part of the email correspondence between employees and customers. Different stakeholders

\section{Customer} service experience management 
JSTP

\section{4}

\begin{tabular}{|c|c|c|c|}
\hline Locus $^{1}$ & Type & Amount $^{2}$ & Amount of data and specifications \\
\hline \multirow[t]{14}{*}{$\begin{array}{l}\text { Train \& Co and } \\
\text { MonITor }\end{array}$} & $\begin{array}{l}\text { Work floor } \\
\text { immersion }\end{array}$ & 58 days & $\begin{array}{l}43 \text { pages consisting of field notes, photos, email } \\
\text { correspondence and company documents }\end{array}$ \\
\hline & $\begin{array}{l}\text { Sessions } \\
\text { Welcome and } Q \& \mathrm{~A}\end{array}$ & 1 & \\
\hline & In-depth workshops & 4 & workshop material (brown papers, post-it and scrap \\
\hline & Strategy and & 3 & papers) \\
\hline & management & & \\
\hline & Training & 5 & \\
\hline & Weekly stand-ups & 9 & \\
\hline & Interviews & & 58 pages consisting of notes and verbatim of audio \\
\hline & $\begin{array}{l}\text { Short }(15- \\
30 \text { minutes })\end{array}$ & 18 & recording \\
\hline & $\begin{array}{l}\text { In-depth (30- } \\
60 \text { minutes) }\end{array}$ & 7 & \\
\hline & Informal gatherings & & 15 pages consisting of field notes and photos \\
\hline & Lunches & 13 & \\
\hline & $\begin{array}{l}\text { Friday afternoon } \\
\text { drinks }\end{array}$ & 5 & \\
\hline & Staff party & 1 & \\
\hline \multirow[t]{14}{*}{ Joint } & Meetings & & 89 pages consisting of field notes, photos and verbatim \\
\hline & First acquaintance & 4 & of audio recording \\
\hline & $\begin{array}{l}\text { Information } \\
\text { gathering }\end{array}$ & 6 & \\
\hline & Formal & 3 & \\
\hline & management & & \\
\hline & Sales & 6 & \\
\hline & Ad hoc & 7 & \\
\hline & $\begin{array}{l}\text { Other (e.g. catch-up/ } \\
\text { update) }\end{array}$ & 6 & \\
\hline & Sessions & & 18 pages consisting of field notes, photos and verbatim \\
\hline & $\begin{array}{l}\text { Small and large } \\
\text { project kickoff }\end{array}$ & 3 & of audio recording \\
\hline & Trainings & 2 & \\
\hline & Other & & 7 pages consisting of field notes, photos and \\
\hline & $\begin{array}{l}\text { Customer and } \\
\text { partner forums }\end{array}$ & 2 & promotional material (folders) \\
\hline & Guided tour & 1 & \\
\hline \multirow[t]{5}{*}{ Customer } & Interviews & & 105 pages consisting of notes and verbatim of audio \\
\hline & $\begin{array}{l}\text { Short }(15- \\
30 \text { minutes })\end{array}$ & 34 & recording \\
\hline & $\begin{array}{l}\text { In-depth (45- } \\
115 \text { minutes) }\end{array}$ & 6 & \\
\hline & Other & & 3 pages consisting of field notes, photos and \\
\hline & Guided tour & 1 & promotional material (folders) \\
\hline
\end{tabular}

Table 2.

Key figures in data collection
Note(s): ${ }^{1}$ The locus points out where the data collection took place. At Train \& $\mathrm{Co}$ and MonITor or customers, respectively, or in joint situations, in which one of the service providers as well as the customers were present, ${ }^{2}$ Amount in sessions or specified otherwise

were involved in the data gathering ranging from HR directors to IT managers and from learning and development (L\&D) representatives to the training participants. Some were DMUs while others fulfilled representative roles.

To meet the condition of creating detailed descriptions (Fetterman, 2019), the ethnographer ensured the level of detail across the different data collection times by 
noting several aspects during the entire journey. This concerned, for example, factual information about the event (time, place, parties and stakeholders involved); exact quotes; the sequences of activities and how they occurred and their possibly relevant histories, behaviors, perceptions and feelings. As ethnographic research involves the researcher (O'Reilly, 2012), the ethnographer took careful notes of his own experiences, thoughts and feelings during data collection. The data were stored in audio (when practically possible and after asking for permission), written and photographic records. The audio recordings were transcribed verbatim, and other data were carefully structured.
Customer service experience management

375

\subsection{Data analysis}

We used a theory-building approach when analyzing our data. This involves moving from the ethnographer's perspective, which consists predominantly of thick descriptions, to one that is more analytical and entwined into the current research (Lok and De Rond, 2013; Van Maanen, 1979). In the complete data analysis, we used an iterative cyclical process, meaning that we continuously moved back and forth among the data, literature and an emerging structure of empirical categories that comprised cyclical reading and analysis of all data (Lok and De Rond, 2013; Miles and Huberman, 1994; Dubois and Gadde, 2002). In this process, we closely observed the critical event, the (altered) CSE, the service provider practices in response to manage CSE and the reaction on behalf of the customer while we continuously remained conscious of the customer journey phases.

We commenced our data analysis by identifying the phases in the customer journey that were specific to our study. We found inspiration in recent B2B literature that has already defined several phases (e.g. Witell et al., 2020) while, at the same time, we were sensitive to the customer journeys specific to our cases. As a result, we distilled five generic phases that were applicable to Train \& Co and MonITor (illustrated in Table 3). While phases two, three and four overlap with the phases previously identified as prebid engagement, negotiation/value proposition, implementation and operations (Brady et al., 2005; Tuli et al., 2007; Witell et al.,

\begin{tabular}{|c|c|}
\hline Customer journey phase & Description \\
\hline $\begin{array}{l}\text { 1. Trigger and problem } \\
\text { analysis }\end{array}$ & $\begin{array}{l}\text { Customers are triggered by issues that hamper their daily processes and } \\
\text { analyze the problem at hand }\end{array}$ \\
\hline $\begin{array}{l}\text { 2. Orientation and } \\
\text { negotiation }^{*}\end{array}$ & $\begin{array}{l}\text { Customers orient towards a possible solution and negotiate a fitting solution } \\
\text { with service providers. Customers specify what needs to be purchased, provide } \\
\text { information about its business operations and current needs through } \\
\text { touchpoints at different actor levels }\end{array}$ \\
\hline 3. Choice and purchase ${ }^{*}$ & $\begin{array}{l}\text { Customers make a choice for the most suitable provider including the best } \\
\text { solution(s), after which customers purchase the solution by agreeing upon, } \\
\text { completing and signing contracts }\end{array}$ \\
\hline $\begin{array}{l}\text { 4. Implementation and } \\
\text { usage }^{*}\end{array}$ & $\begin{array}{l}\text { Customers implement (oftentimes together with the service provider) the } \\
\text { solution(s) by making it (them) fit with organizational systems and processes. } \\
\text { Customers, oftentimes the end-users, use the solution by actually utilizing it in } \\
\text { their daily processes. Occasionally, in large projects, usage may overlap for a } \\
\text { certain period with implementation }\end{array}$ \\
\hline 5. Evaluation and follow-up & $\begin{array}{l}\text { Customers evaluate their service experience of the service provider's overall } \\
\text { service and solution, either individually or jointly with the service provider. } \\
\text { They provide a follow-up, by either being loyal to the service provider or looking } \\
\text { for a different solution elsewhere } \\
\text { Note: this phase also includes features such as "service safeguarding" in which } \\
\text { the service provider ensures that the solution will be properly embedded in the } \\
\text { organization in the long term }\end{array}$ \\
\hline
\end{tabular}

Customer journey phase

1. Trigger and problem analysis

2. Orientation and negotiation $^{*}$

3. Choice and purchase*

. Implementation and usage*

Note(s): *Partly adopted from Brady et al. (2005); Tuli et al. (2007) and Witell et al. (2020)
Table 3.

Five customer journey phases applicable to MonITor and Train \& Co 
JSTP

31,3

2020), we expanded the customer journey as our data specified two additional phases. First, before any "orientation and negotiation" or "prebid engagement", customers are triggered, face challenges or problems and analyze them accordingly. Second, after "implementation and usage" or "operations", customers evaluate their trajectory with service providers and provide a follow-up, either prolongation or searching for alternative solutions.

The customer journey provided support in further arranging and analyzing our data. We went through our data and identified critical events. For each event, we noted where it happened in the customer journey and classified it accordingly. We described the critical event, followed by the actions taken by the service provider, and the outcome for the customers in terms of their satisfaction and service experience. Subsequently, we distilled crucial "first-order" service provider practices using an open coding strategy that analyzed every case in detail to filter out a myriad of categories (Gioia et al., 2013; Strauss and Corbin, 1998). We progressed with axial coding to identify similarities and differences between the categories. This process reduced all germane categories into a more manageable group of "second-order" practice categories (Gioia et al., 2013; Strauss and Corbin, 1998). Our cases were of the same structure while still preserving as much of the richness of our data as possible. By closely considering how the practices are organized and how the service providers employ them, we were able to make two crosssections in the typology of practices, namely the mode of organization (ad hoc versus regular) and the mode of engagement (reactive versus proactive). By including the outcome for the customer, we were able to differentiate the effect of the service provider practices on CSE (restore versus bolster). We concluded our analysis by mapping out all practices across this typology to show the patterns of service provider practices throughout the entire customer journey. This includes the recurrence of practices divided into occasionally, sometimes and frequently. Occasionally signifies that the practices are present once, sometimes twice and frequently three times. The first author was responsible for the in-depth analysis, the second author cross-checked everything and randomly analyzed cases himself in depth, and the third author sensechecked the entire process including the findings.

\section{Findings}

\subsection{Identifying service provider practices}

Our findings show that the practices conducted by service providers in managing CSE are multifold and occur in different phases throughout the customer journey. Table 4 summarizes these practices while their narratives can be found in Appendix 1. For the sake of clarity, we listed illustrations of nine selected cases documented across all phases of the customer journey. These nine cases were exemplary for our study and were selected out of a total of 18 cases (eight from Train \& Co and ten from MonITor). All 18 cases can be found in the Table of online Appendix 2. The nine exemplary cases (Appendix 1) serve as narratives consisting of illustrative quotes and field notes in combination with an accompanying text.

\subsection{Interpreting the nature and type of service providers' practices}

This section highlights and homes in on the nature and type of service provider practices and uncovers commonalities and differences. The practices contain several repertoires, each with its own characteristics. We categorized these characteristics into "modes of organization" and "modes of engagement." The modes of organization imply the ways in which service providers organize their practices to manage CSE. We identified two forms: practices that were organized in an "ad hoc" fashion and those enacted routinely and on a "regular" basis. An ad hoc practice is one that occurs spontaneously without an envisioned routine for how to deal with an event. Regular practices are embedded in and facilitated by organizational procedures. The modes of 


\begin{tabular}{|c|c|c|c|c|c|c|c|c|c|c|c|}
\hline \multirow{2}{*}{$\begin{array}{l}\text { Service provider } \\
\text { practice }\end{array}$} & \multirow[b]{2}{*}{ Description } & \multicolumn{9}{|c|}{ Illustrated in narrative in Appendix 1} & \multirow{2}{*}{$\begin{array}{r}\text { Customer } \\
\text { service }\end{array}$} \\
\hline & & 1 & 2 & 3 & 4 & 5 & 6 & 7 & 8 & 9 & \\
\hline $\begin{array}{l}\text { 1. Provide } \\
\text { constructive } \\
\text { advice }\end{array}$ & $\begin{array}{l}\text { The service provider advises the customer } \\
\text { in a constructive and adequate fashion } \\
\text { about what would be best for the customer }\end{array}$ & $\mathrm{X}$ & & $\mathrm{X}$ & & & & & & $\mathrm{X}$ & $\begin{array}{r}\text { experience } \\
\text { management }\end{array}$ \\
\hline $\begin{array}{l}\text { 2. Tailor value } \\
\text { promise }\end{array}$ & $\begin{array}{l}\text { The service provider customizes its } \\
\text { offering to the customer's situation and } \\
\text { needs }\end{array}$ & & & & $\mathrm{X}$ & & & & & & 377 \\
\hline $\begin{array}{l}\text { 3. Analyze the } \\
\text { problem } \\
\text { thoroughly }\end{array}$ & $\begin{array}{l}\text { The service provider analyzes the } \\
\text { customer's problem carefully by, for } \\
\text { example, asking critical questions or } \\
\text { performing a root cause analysis }\end{array}$ & $\mathrm{X}$ & & $\mathrm{X}$ & & & & & & $\mathrm{X}$ & \\
\hline $\begin{array}{l}\text { 4. Solve problems ad } \\
\text { hoc }\end{array}$ & $\begin{array}{l}\text { The service provider solves the problem at } \\
\text { hand immediately in situ }\end{array}$ & & & & & & $\mathrm{X}$ & & $\mathrm{X}$ & & \\
\hline $\begin{array}{l}\text { 5. Steer toward } \\
\text { solutions }\end{array}$ & $\begin{array}{l}\text { The service provider undertakes action } \\
\text { that accommodates or is aimed toward a } \\
\text { solution for the customer }\end{array}$ & & $\mathrm{X}$ & & & $\mathrm{X}$ & $\mathrm{X}$ & & $\mathrm{X}$ & $\mathrm{X}$ & \\
\hline $\begin{array}{l}\text { 6. Manage the } \\
\text { relationship } \\
\text { strategically }\end{array}$ & $\begin{array}{l}\text { The service provider takes care of the } \\
\text { supplier-customer relationship that } \\
\text { accommodates a long-term collaboration }\end{array}$ & & $\mathrm{X}$ & & $\mathrm{X}$ & $\mathrm{X}$ & & & & & \\
\hline $\begin{array}{l}\text { 7. Take decisive } \\
\text { action }\end{array}$ & $\begin{array}{l}\text { The service provider undertakes resolute } \\
\text { and firm action by standing its ground }\end{array}$ & & & $\mathrm{X}$ & $\mathrm{X}$ & & & & $\mathrm{X}$ & & \\
\hline $\begin{array}{l}\text { 8. Manage } \\
\text { expectations }\end{array}$ & $\begin{array}{l}\text { The service provider manages the } \\
\text { customer's expectations in advance to } \\
\text { ensure alignment with expectations }\end{array}$ & & & $\mathrm{X}$ & & & $X$ & & & & \\
\hline $\begin{array}{l}\text { 9. Empathize with } \\
\text { the customer }\end{array}$ & $\begin{array}{l}\text { The service provider tries to understand } \\
\text { the customer's situation by empathizing } \\
\text { with the customer }\end{array}$ & & & & & $\mathrm{X}$ & & $\mathrm{X}$ & $\mathrm{X}$ & & $\begin{array}{r}\text { Table 4.; } \\
\text { Service providers' } \\
\text { practices in managing } \\
\text { customer service }\end{array}$ \\
\hline $\begin{array}{l}\text { 10. Stabilize the } \\
\text { situation }\end{array}$ & $\begin{array}{l}\text { The service provider conducts repair work } \\
\text { to temporarily patch/recover the situation }\end{array}$ & & & & & & & $\mathrm{X}$ & & & $\begin{array}{l}\text { experience across the } \\
\text { customer journey }\end{array}$ \\
\hline
\end{tabular}

engagement consist of reactive engagement and proactive engagement. In the former, the service provider helps the customer in an adequate way by providing prompt service (Parasuraman et al., 1988; Virlée et al., 2020) while, in the latter, the service provider initiates inventive support that enables it to coproduce solutions for and with the customer. In this, we find a link between how the modes of engagement shape CSE. Reactive engagement typically restores CSE, i.e. repairs or stabilizes CSE and returns it to its regular order (Van Vaerenbergh et al., 2019). Proactive engagement bolsters CSE (i.e. boosts or (additionally) enhances CSE to surpass a regular order) and may, for example, exceed customer expectations to a surprising degree, which is more commonly known as customer delight (e.g. Ball and Barnes, 2017; Guidice et al., 2020). To substantiate this typology of practices, we briefly exemplify each practice and refer to the narratives in the Appendix 1 for further detail.

First, illustration 6 depicts an example in which ad hoc practices with reactive engagement occurred. The critical event arose due to a lack of clarity in agreements between the customer and MonITor in the choice and purchase phase. The project leader from the customer's organization stated, "Which agreements did you make with our developer?", clearly showing the active role of customers in effective working relationships in terms of project governance (Bettencourt et al., 2002; Virlée et al., 2020) in the coproduction process of solutions. Immediate action was necessary on behalf of the director of MonITor, and he responded, "Yesterday, Igot an email from your developer with several questions based on the answers I gave him in earlier email correspondence. We agreed that I will contact our development department, and depending on how soon I get a response, I will follow-up with you. Based on this, I promise to send you the formal agreement before the end of next week." To settle CSE, the director acted 
JSTP 31,3 directly, in a solution-oriented manner, and dealt with the problem as it occurred. Without any recorded organizational guidelines for such events, only spontaneous action on an ad hoc basis was undertaken to restore CSE. The project leader can continue his work, which is represented well in the following quote: "Perfect. That's sufficient for me because then I can set up and arrange internal issues. Super. Thanks very much, and we will keep in touch then."

Second, regular practices through reactive engagement are exemplified by illustration 3 . Beforehand, the customer's L\&D manager had already created insights into the needs of all the employees of the two departments. Despite having these insights, she experienced challenges with training averse employees as those employees did not want to take part in training at all or were only to participate in short courses. This critical event arose in an important customer journey phase for both the customer and Train \& Co. Especially, during the orientation and negotiation phase - a crucial phase before a customer makes a purchase decision - it is commonly accepted by Train \& Co's team that they need to be clear upfront. To do so, Train \& Co's employees know that they should first properly understand the situation at hand, and thus they analyze the problem thoroughly. To set the stage for the customer, Train \& Co's account manager manages expectations by acting decisively if necessary. "Only half a day?! That's very short, too brief, and something I would not recommend. It's more like a workshop instead of a real training. But tell me, what exactly is the reason they only want a maximum of one day and half a day of training?" This works in parallel with proactive advice from Train \& Co's trainer. "Look, in one day you can schedule quite a complete training. Im able to discuss general theories and concepts. However, in half a day, that's impossible. Half a day is more like a workshop to give people an idea what the training is about. If you choose half a day, I advise incorporating another half a day later to explain the methodology and give some practical exercises to better embed the knowledge in people's minds and bridge the theory to practice. This is simply not possible in half a day. And of course, if you insist on your initial ideas, be my guest, but I strongly discourage it because it is not effective." Such a mode of organization is already routinely enacted by Train \& Co and aims to recover CSE. Despite the customer's L\&D manager being skeptical earlier in that meeting to manage and convince internal stakeholders, she seemed to show more confidence. Finally, constructive advice on the customer's planning from Train \& Co helped the L\&D manager sharpen her message, as evident in the following quote: "I get your point, and my proposition is that I will get in touch with the manager of both departments to point out exactly what you mentioned." Thus, she was able to proceed with her work and act as an advocate for the service provider within her firm (Bettencourt et al., 2002; Virlée et al., 2020), which helped her to reach her goals.

Third, illustration 8 describes an ad hoc approach with proactive engagement in the implementation and usage phase. The customer's head of back-office faced problems. When breakdowns occurred that directly impacted work processes, he did not have insight into what exactly was going wrong. "See. .. I am missing thresholds over here. On this dashboard, I need more information that thoroughly shows me what's going on. This is too superficial." Despite MonITor's customer service helping him out well, he was looking for more stability and continuity in his back-office processes. MonITor's account manager demonstrated that he understood the situation and steered him toward a solution, and, as a result, he came up with initiatives that the customer had not asked for or previously considered. "I do not see any screens showing the dashboards. This is absolutely necessary because it shows you what's happening and what you need to do." After turning the complication into a stable situation (i.e. restoring CSE), MonITor's representative spontaneously proposed a somewhat surprising solution, making the customer even more satisfied and causing the previously stable CSE to be surpassed. "I fully agree with what you just said. It only comes to life if there are screens present in my department. Everybody should be able to see what's happening."

Finally, we illuminate regular practices with proactive engagement in illustration 4 . Train $\& C_{0}$ is familiar with the orientation and negotiation phase, which is a moment of truth for all 
involved parties and can make a difference. At first, Train \& Co's account manager was overwhelmed by the scattered needs the customer pointed out. Such a lack of focus would not be an effective manner of training employees. He took decisive action by giving pushback while managing the strategically relationship in situ and spontaneously by not merely focusing on big sales opportunities but thinking on the customer's behalf. He proactively tailored his offering to the customer's situation. The customer felt understood through the initiated empathetic action and behavior by Train \& Co's representatives. "I remember when Michael told me, 'If you want all of this, you should look for another service provider. I'm not going to commit myself to this.' I really appreciated the honest feedback, and Im happy he gave me pushback. My plans were too ambitious. Michael sincerely advocated for what was good for us and did not act from a commercial point of view." The reactive practices were conducted ad hoc and regularly created the basis for further proactive engagement on behalf of the service provider. This occurred in the form of tailoring the value promise specifically to the customer's situation. Such a practice occurs in both a routinized fashion and with proactive engagement, resulting in bolstered CSE.

Figure 1 synthesizes the findings in a circumplex typology of service provider practices in managing CSE throughout the customer journey. The circumplex typology illustrates the mode of organization (ad hoc or regular) and mode of engagement (reactive or proactive), which are laid out on the $X$ - and $Y$-axes, respectively. The mode of engagement plays a role in shaping CSE (restoring or bolstering). To clearly display this effect on CSE, we label the slightly gray top halfmoon as "bolstering" CSE and the white bottom half-moon as "restoring" CSE. The figure also shows the recurrence of all practices, categorized into occasionally, sometimes and frequently.

Based on this categorization of service provider practices, we distilled the following key observations. Although their function may vary depending on the phase in the customer journey, the majority of service provider practices are reactive in nature and aim to restore CSE. They are evenly distributed across all phases of the customer journey; however, we noted that regular practices have a higher recurrence than practices conducted in an ad hoc fashion. Practices by proactive engagement that bolster CSE are rarer. When they occur, the service providers proactively engage in a routinized way with practices mainly in the negotiation and orientation and choice and purchase phases. Notably, in the former, tailoring the value promise is strongly present, followed by steering toward a solution and empathizing with the customer. Nevertheless, strategically managing customer relations through ad hoc engagement is required. The majority of routinized practices with proactive engagement seem to transition toward practices that are organized on an ad hoc basis in later phases (four and five) of the customer journey.

More closely considering the scattered picture of the ten practices (as seen in Table 4) and their characteristics uncovers that "iterative learning and adapting" seems to be an overall organizational theme. This allows service providers to remain agile in the process of managing CSE and to improve their CSE management capabilities on a continuous basis. The approach is shown in illustration 9, in which service providers' employees typically gather after meetings with a customer to discuss key takeaways and points for improvement. For example, the account manager suggests that the trainer would join him next time in customer meetings because of the excellent CSE delivered.

\section{Discussion}

\subsection{Reflections on CSE management practices}

The current status in the literature is that CSE is conceived as multifaceted (Becker and Jaakkola, 2020), dynamic and context dependent (e.g. Helkkula et al., 2012a), and that customer journeys are complex and heterogeneous, particularly in the B2B context (e.g. Grönroos, 2017; Lemon and Verhoef, 2016; Norton and Pine, 2013). Hence, the

\section{Customer service experience management}

379 
JSTP

31,3

380

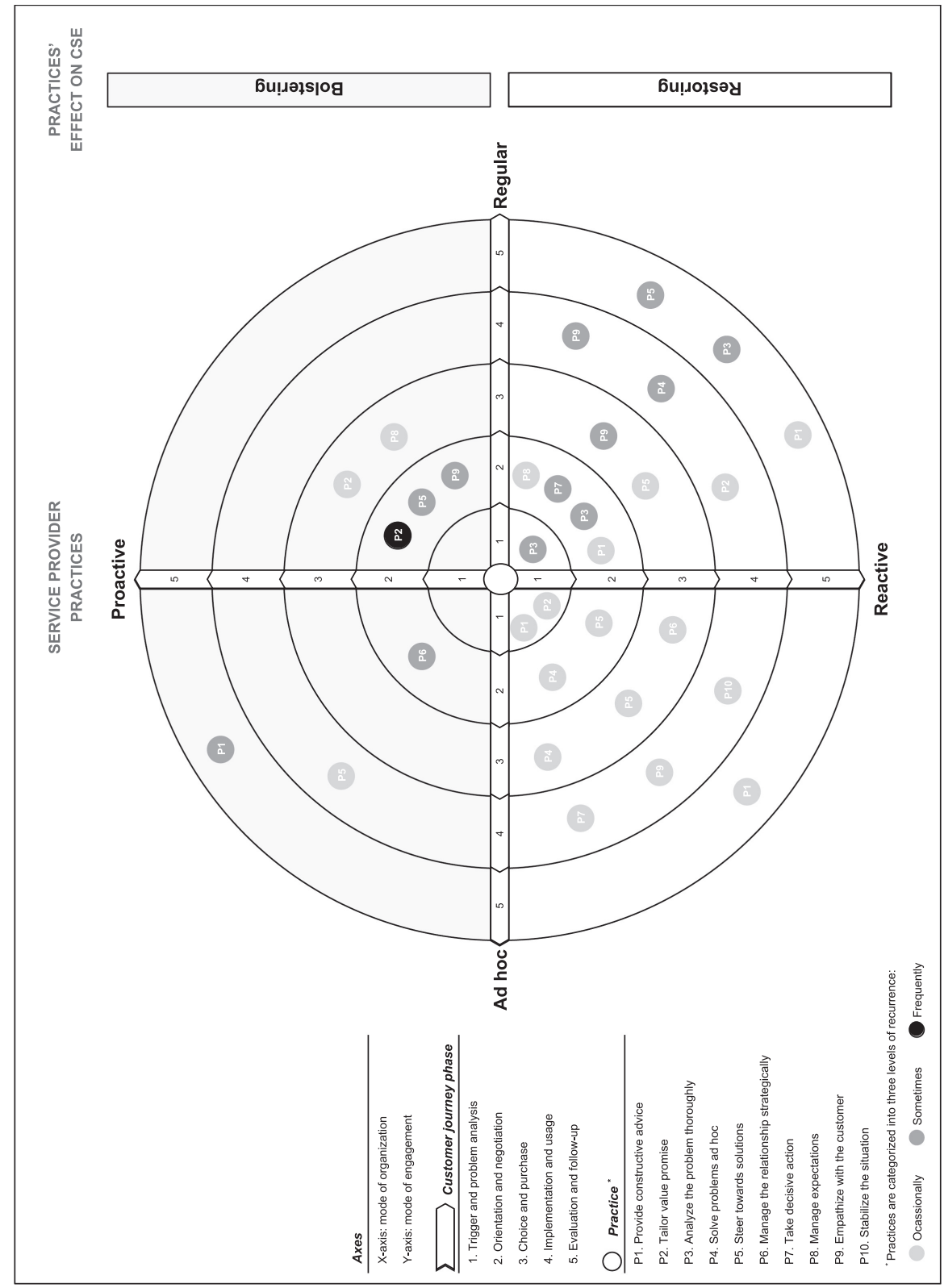

Figure 1.

Circumplex typology of service provider practices in managing customer service experience (CSE) throughout the customer journey 
conceptualization of the management of CSE in customer journeys presents difficulties (De Keyser et al., 2020; McColl-Kennedy et al., 2019; Witell et al., 2020; Zolkiewski et al., 2017) and seems to be a black box in terms of both theory and practice (e.g. Ostrom et al., 2015). The purpose of this study was to jump into this black box and explore from within the efforts of two service providers in knowledge-intensive industries to manage CSE across multiple phases in the customer journey from a dyadic perspective, that is, relationally with customers. This focus on investigating service providers' CSE management practices is especially favorable because it takes into account the interactive nature of customer-service provider relationships throughout the customer journey. In scrutinizing these managerial practices, we distilled specific practices that varied by function (the subject of the practice) and form, that is, how practices are organized at the level of the service provider and their modes of engagement during interactions with customers. Each of these four practices, with different levels of presence, may influence CSE differently: either by restoring or bolstering. For the reasons provided, we decided to examine these practices at times when service providers and customers were confronted with a critical event in their relationship.

The findings uncovered a detailed picture of ten practices with four repertoires of service provider practices in CSE management with three levels of presence. Practices 3, 8 and 9 are in line with the earlier research (identifying root causes (McColl-Kennedy et al., 2019), for example, the management of expectations to prevent a service performance gap (Bitner et al., 2010; Følstad and Kvale, 2018) and initiation (Van Vaerenbergh et al., 2019) and emotional competence through empathy (Virlée et al., 2020; Delcourt et al., 2016)). The reactive mode of engagement fits well with the previous service research that indicated responsiveness (i.e. reactiveness) as a key antecedent in delivering value (Parasuraman et al., 1988; Medberg and Grönroos, 2020; Virlée et al., 2020). Iterative learning and adaptation, as an overall organizational theme, allows service providers to remain agile in the process of managing CSE and to continuously improve their CSE management capabilities. This is in line with the previous service research that indicated the extraction of valuable customer insights across the customer journey (McColl-Kennedy et al., 2019) to, for instance, enhance customer loyalty (Lemon and Verhoef, 2016). Furthermore, we confirm the active role played by customers in the coproduction of solutions through, for example, project governance, acting as internal vocal advocates (Bettencourt et al., 2002; Virlée et al., 2020) or sharing information and feedback, which is part of "colearning" (Tommasetti et al., 2017; McColl-Kennedy et al., 2012).

In the circumplex typology, we show that practices vary by modes of organization and engagement and thus switch from ad hoc to regular and from reactive to proactive in shaping CSE. In essence, CSE is triggered by a critical event, and what service providers do and how they do it are relevant issues. We also observed that service provider practices and CSE have a reciprocal relationship. In a sense, the practices shape CSE, and CSE in turn determines the practices that are necessary to manage it accordingly.

We observed that CSE evolves idiosyncratically for customer accounts due to practices undertaken by the service providers. In other words, service provider practices affect the CSE of each individual account. This, in turn, works as a double-edged sword that offers opportunities to manage customer accounts individually but entails a complex challenge of simultaneously managing them all. While CSE management throughout the customer journey remains complex, the findings, especially the circumplex typology, create a clearer and distilled picture of how and when the distinctive repertoires of service provider practices manifest in phases of the customer journey.

Finally, we show that there is a thin line between practices that manage CSE and those that are detrimental to it. Even though some practices were conducted with good intentions, some were detrimental and even led to what we perceived as CSE destruction (see cases 3.1, 4.4 and 5.3 in the online Appendix 2). These practices have in common that they seem to lack coordination (in the choice and purchase and implementation and usage phases); they show

\section{Customer service experience management}

381 
JSTP

31,3 evidence of poor communication with customers and avoidance of customer requests (in the implementation and usage phase) or indicate a tendency toward opportunistic behavior by the service provider during sales encounters, overtly showing commercial exploitation (in the evaluation and follow-up phase).

\subsection{Theoretical contributions}

This study attempts to make theoretical contributions to four domains. First, we contribute to the domain of CSE management throughout the customer journey in a B2B context. To date, the literature has adopted either the customer's (De Keyser et al., 2020; McColl-Kennedy et al., 2019; Zolkiewski et al., 2017) or an organizational (service provider) point of view (Witell et al., 2020) in understanding CSE management and has often remained on a rather strategic level. Since this omits what occurs in interaction, a dyadic, microlevel perspective has proven useful to focus on CSE management in ongoing relationships between service providers and customers. It has revealed everyday operational practices to shape CSE with overlaps in function but variations in modes of organization and engagement. In doing so, the paper poses a finer-grained picture of customer responses to critical events and the ways in which service providers seek to restore CSE through reactive actions (Van Vaerenbergh et al., 2019) or to bolster CSE by engaging proactively and in an inventive solution-oriented manner. We brought these findings together in a convenient circumplex typology of CSE management practices that can help steer future discussion and research on such practices. Our study also demonstrated how and when service providers manage CSE dynamically in the customer journey. Thus, we contribute to the existing literature that has described such practices in more functional terms such as empathy and initiation (Van Vaerenbergh et al., 2019), identifying root causes (McColl-Kennedy et al., 2019) and managing expectations (Bitner et al., 2010; Følstad and Kvale, 2018). We expand on these functional descriptions by introducing the notion of modes of organization and engagement that shape CSE. We add to the existing literature that a proactive mode of engagement bolsters CSE, which is another level as opposed to restoring or repairing CSE through reactiveness and empathy (Medberg and Grönroos, 2020; Parasuraman et al., 1988; Virlée et al., 2020). While our study focused on the identification of the service providers' CSE management practices, our dyadic approach also allowed us to observe the customers' role in the coproduction of solutions. Along the lines of the previous service literature (Bettencourt et al., 2002; Tommasetti et al., 2017; Virlée et al., 2020; McColl-Kennedy et al., 2012), we witnessed that customers contribute to, for example, project governance; act as internal vocal advocates or share information and feedback.

In this way, we also contribute to the emerging body of solutioning literature (see, for example, Hakanen and Jaakkola (2012) and Storbacka (2011)) by showing that exploring solutions with customers requires a proactive, solution-oriented attitude from service providers rather than only reactiveness. We draw attention to the importance of organizing in managing CSE. We uncovered two modes of organization, both of which appear relevant in effective CSE management. As such, we offer an additional design criterion for scholarship interested in CSE management in customer journey design (De Keyser et al., 2020; Bolton et al., 2018; Homburg et al., 2017).

Next, we contribute to the literature on CSE (e.g. Ellway and Dean, 2016; Helkkula et al., 2012a; Jaakkola et al., 2015). This stream of literature has primarily conceptualized the nature of the customer experience as fragile, dynamic, temporal and idiosyncratic and how it varies due to contingencies in value-creation processes including past and collective experiences. We contribute to this stream by highlighting the important role of service providers in their efforts to influence customer experiences in ongoing value-creation practices. This influence becomes especially critical in B2B settings where customer journeys are conceived as more complex due to the multiple actors involved, each with distinct roles, responsibilities and experiences. 
Finally, there is an increasing call for more evidence-based research embracing a microperspective in the study of service provider-customer relationships (Grönroos and Voima, 2013; Norton and Pine, 2013), particularly in the CSE management research (De Keyser et al., 2020; Verleye, 2019; Witell et al., 2020). We contributed to this call by drawing on a multiple case study in which we adopted ethnography to grasp the logic of practice guided by our research question. We showed how critical events, which can and will occur in such knowledgeintensive-driven relationships, constitute an important source of action on behalf of both the service provider and the customer. In our case, the intention was to uncover the differences and commonalities in the CSE management practices of both service providers.

\subsection{Managerial implications}

While managing CSE is a daunting task for organizations (Edelman and Singer, 2015; Rawson et al., 2013), and it is even more complex in B2B contexts, it remains pivotal for organizations to create satisfied and loyal customers. Based on the findings, this paper offers practitioners a way to overcome this challenge of managing CSE through the underlying circumplex typology (Figure 1). Such typology can be deployed as a supportive tool to better understand and master CSE management during critical events or as practical guidance in the design of customer journeys and touchpoints. The circumplex typology indicates that practices vary by the modes of organization and engagement, even if they have similar functions, and that some of them reoccur more often than others in different phases. This implies that customer journeys and the practices oriented to shape CSE cannot be scripted ahead of time but require sufficient space to allow for spontaneous actions based on contingencies that can and will occur in the customer journey. Thus, service providers should be aware that different CSE management practices may have different effects on CSE. This implies that service providers must take into account that some practices appear as ad hoc and perhaps messy while others can be organized in a more scripted manner, especially those that reoccur substantively across multiple phases in the customer journey. This may require a so-called ambidextrous mindset that helps to adopt and orchestrate these different modes of organization. It also calls for a degree of flexibility on behalf of the service providers and their front and back-office staff. Furthermore, service providers should be aware of the extent to which practices are, or should be, present in the different phases in the customer journey. For example, in early customer journey phases when customers are orienting to a possible solution and negotiating with service providers, it is apparent that embedding and tailoring one's value promise as a regular CSE management practice can bolster CSE and may convince a potential customer. Finally, based on the infusion of the dyadic perspective taken in this study, we underscore the importance of dialogical and collaborative processes in CSE management. In other words, the customer participates in the very practice that essentially helps in shaping their CSE.

\subsection{Limitations and future research}

This research is built on an ethnographic approach to examine how service providers manage CSE during critical events throughout the customer journey. We strongly believe that the approach taken and our findings can serve as an impetus for other researchers to further investigate how such practices affect specific dimensions of CSE such as temporality (past, present and future) and collective versus individual CSE.

The point of departure was as follows: How do B2B service providers, in business relationships, manage CSE in terms of practices throughout the various phases in the customer journey? Along the way, we also discovered practices that destroy CSE. It would be valuable to improve our understanding of CSE-damaging practices. Quantitative research could provide additional insights, for instance, by helping to rank the role of various practices in terms of their impact on CSE (i.e. organizational measures of success).

\section{Customer service experience management}

383 
JSTP 31,3

This article examined the actions of service providers in light of the CSE of multiple customers based on critical events in different phases of the customer journey. This implies that we were not able to analyze how the outcome of a managerial intervention in one phase informs $\mathrm{CSE}$ in the next customer journey phase of a single customer. It would be interesting to examine how CSE is shaped by subsequent managerial actions by the service provider, which can give further detail to the organizational theme that we identified as "iterative learning and adapting". Therefore, future research might focus on how several individual customers' CSEs vary and are managed in the consecutive phases of the customer journey to identify different "best practice paths", which would yield more prescriptive guidance for practice. For instance, an interesting question would be as follows: what different routes exist in CSE management?

In our research, we observed different actors at the service provider as well as the participating customer organizations. It might be worthwhile to involve a stakeholder (internal and external) mapping approach to gain a clearer picture of how decision-making and problem-solving staff are involved in CSE management at the department/unit level as ideas about appropriate practices might vary in each unit. Furthermore, since customer relationships are increasingly maintained through digital technology, we encourage the involvement of multichannel and multiinterface perspectives to enhance our understanding of what the interplay between technology and CSE management looks like throughout the customer journey.

A final remark to be made is that this study focused specifically on a knowledge-intensive consulting and training service context. In other contexts, CSE may appear more or less stable, and different practices may apply in another field with contrasting impacts on CSE. We therefore encourage scholars to build on our framework, which may give them some empirical foothold, while remaining open to new insights that are necessary to expand our knowledge on managing CSE.

\section{References}

Aarikka-Stenroos, L. and Jaakkola, E. (2012), "Value co-creation in knowledge intensive business services: a dyadic perspective on the joint problem solving process", Industrial Marketing Management, Vol. 41 No. 1, pp. 15-26.

Ball, J. and Barnes, D.C. (2017), "Delight and the grateful customer: beyond joy and surprise", Journal of Service Theory and Practice, Vol. 27 No. 1, pp. 250-269.

Becker, L. and Jaakkola, E. (2020), "Customer experience: fundamental premises and implications for research", Journal of the Academy of Marketing Science, Vol. 48 No. 4, pp. 630-648.

Berry, L.L., Carbone, L.P. and Haeckel, S.H. (2002), "Managing the total customer experience", MIT Sloan Management Review, Vol. 43 No. 3, pp. 85-90.

Berry, L.L., Wall, E.A. and Carbone, L.P. (2006), "Service clues and customer assessment of the service experience: lessons from marketing”, Academy of Management Perspectives, Vol. 20 No. 2, pp. 43-57.

Bettencourt, L.A., Ostrom, A.L., Brown, S.W. and Roundtree, R.I. (2002), "Client Co-production in knowledge-intensive business services”, California Management Review, Vol. 44 No. 4, pp. 100-128.

Bitner, M.J., Zeithaml, V.A. and Gremler, D.D. (2010), "Technology's impact on the gaps model of service quality", in Maglio, P.P., Kieliszewski, C.A. and Spohrer, J.C. (Eds), Handbook of Service Science, Springer US, Boston, MA, pp. 197-218.

Bolton, R.N., McColl-Kennedy, J.R., Cheung, L., Gallan, A., Orsingher, C., Witell, L. and Zaki, M. (2018), "Customer experience challenges: bringing together digital, physical and social realms", Journal of Service Management, Vol. 29 No. 5, pp. 776-808.

Brady, T., Davies, A. and Gann, D.M. (2005), "Creating value by delivering integrated solutions", International Journal of Project Management, Vol. 23 No. 5, pp. 360-365. 
Cortez, R.M. and Johnston, W.J. (2017), "The future of B2B marketing theory: a historical and prospective analysis", Industrial Marketing Management, Vol. 66, pp. 90-102.

Court, D., Elzinga, D., Mulder, S. and Vetvik, O.J. (2009), “The consumer decision journey”, McKinsey Quarterly, Vol. 3 No. 3, pp. 96-107.

Czarniawska, B. (2004), "On time, space, and action nets”, Organization, Vol. 11 No. 6, pp. 773-791.

De Keyser, A., Verleye, K., Lemon, K.N., Keiningham, T.L. and Klaus, P. (2020), "Moving the customer experience field forward: introducing the touchpoints, context, qualities (TCQ) nomenclature", Journal of Service Research, Vol. 23 No. 4, pp. 433-455, doi: 10.1177/1094670520928390.

Delcourt, C., Gremler, D.D., van Riel, A.C.R. and van Birgelen, M.J.H. (2016), "Employee emotional competence:construct conceptualization and validation of a customer-based measure", Journal of Service Research, Vol. 19 No. 1, pp. 72-87.

Dubois, A. and Gadde, L.-E. (2002), "Systematic combining: an abductive approach to case research", Journal of Business Research, Vol. 55 No. 7, pp. 553-560.

Echeverri, P. and Skålén, P. (2011), "Co-creation and co-destruction: a practice-theory based study of interactive value formation", Marketing Theory, Vol. 11 No. 3, pp. 351-373.

Edelman, D.C. and Singer, M. (2015), "Competing on customer journeys", Harvard Business Review, Vol. 93 No. 11, pp. 88-100.

Edvardsson, B. and Roos, I. (2001), "Critical incident techniques: towards a framework for analysing the criticality of critical incidents", International Journal of Service Industry Management, Vol. 12 No. 3, pp. 251-268.

Edvardsson, B., Enquist, B. and Johnston, R. (2005), "Cocreating customer value through hyperreality in the prepurchase service experience", Journal of Service Research, Vol. 8 No. 2, pp. 149-161.

Eggert, A., Ulaga, W., Frow, P. and Payne, A. (2018), "Conceptualizing and communicating value in business markets: from value in exchange to value in use", Industrial Marketing Management, Vol. 69, pp. 80-90.

Ellway, B.P. and Dean, A.M. (2016), "The reciprocal intertwining of practice and experience in value creation", Marketing Theory, Vol. 16 No. 3, pp. 299-324.

Fetterman, D.M. (2019), Ethnography: Step-by-step, SAGE Publications, London.

Flanagan, J.C. (1954), “The critical incident technique”, Psychological Bulletin, Vol. 51 No. 4, pp. 327-358.

Følstad, A. and Kvale, K. (2018), "Customer journeys: a systematic literature review”, Journal of Service Theory and Practice, Vol. 28 No. 2, pp. 196-227.

Forkmann, S., Henneberg, S.C., Witell, L. and Kindström, D. (2017), "Driver configurations for successful service infusion”, Journal of Service Research, Vol. 20 No. 3, pp. 275-291.

Geertz, C. (1994), "Thick description: toward an interpretive theory of culture", in Martin, M. and McIntyre, L.C. (Eds), Readings in the Philosophy of Social Science, MIT Press, Cambridge (MA), London, pp. 213-231.

Gioia, D.A., Corley, K.G. and Hamilton, A.L. (2013), "Seeking qualitative rigor in inductive research: notes on the Gioia methodology", Organizational Research Methods, Vol. 16 No. 1, pp. 15-31.

Grönroos, C. and Gummerus, J. (2014), "The service revolution and its marketing implications: service logic vs service-dominant logic", Managing Service Quality, Vol. 24 No. 3, pp. 206-229.

Grönroos, C. and Voima, P. (2013), "Critical service logic: making sense of value creation and co-creation", Journal of the Academy of Marketing Science, Vol. 41 No. 2, pp. 133-150.

Grönroos, C. (1984), "A service quality model and its marketing implications”, European Journal of Marketing, Vol. 18 No. 4, pp. 36-44.

Grönroos, C. (2011), "Value co-creation in service logic: a critical analysis", Marketing Theory, Vol. 11 No. 3, pp. 279-301.

Grönroos, C. (2017), "On value and value creation in service: a management perspective", Journal of Creating Value, Vol. 3 No. 2, pp. 125-141.
Customer service experience management

385 
JSTP 31,3

Guidice, R.M., Barnes, D.C. and Kinard, B.R. (2020), "Delight spirals: the cause and consequence of employee perceived customer delight”, Journal of Service Theory and Practice, Vol. 30 No. 2, pp. $149-170$.

Gummerus, J. (2013), "Value creation processes and value outcomes in marketing theory: strangers or siblings?”, Marketing Theory, Vol. 13 No. 1, pp. 19-46.

Hakanen, T. and Jaakkola, E. (2012), "Co-creating customer-focused solutions within business networks: a service perspective", Journal of Service Management, Vol. 23 No. 4, pp. 593-611.

Halinen, A., Salmi, A. and Havila, V. (1999), "From dyadic change to changing business networks: an analytical framework", Journal of Management Studies, Vol. 36 No. 6, pp. 779-794.

Halvorsrud, R., Folstad, A. and Kvale, K. (2016), "Improving service quality through customer journey analysis", Journal of Service Theory and Practice, Vol. 26 No. 6, pp. 840-867.

Helkkula, A., Kelleher, C. and Pihlström, M. (2012a), "Characterizing value as an experience: implications for service researchers and managers", Journal of Service Research, Vol. 15 No. 1, pp. 59-75.

Helkkula, A., Kelleher, C. and Pihlström, M. (2012b), "Practices and experiences: challenges and opportunities for value research", Journal of Service Management, Vol. 23 No. 4, pp. 554-570.

Helkkula, A. (2011), "Characterising the concept of service experience", Journal of Service Management, Vol. 22 No. 3, pp. 367-389.

Holmqvist, J., Visconti, L.M., Grönroos, C., Guais, B. and Kessous, A. (2020), "Understanding the value process: value creation in a luxury service context", Journal of Business Research, Vol. 120, pp. 114-126.

Homburg, C., Jozić, D. and Kuehnl, C. (2017), "Customer experience management: toward implementing an evolving marketing concept", Journal of the Academy of Marketing Science, Vol. 45 No. 3, pp. 377-401.

Jaakkola, E., Helkkula, A. and Aarikka-Stenroos, L. (2015), "Service experience co-creation: conceptualization, implications, and future research directions", Journal of Service Management, Vol. 26 No. 2, pp. 182-205.

Jain, R., Aagja, J. and Bagdare, S. (2017), "Customer experience - a review and research agenda", Journal of Service Theory and Practice, Vol. 27 No. 3, pp. 642-662.

Lavidge, R.J. and Steiner, G.A. (1961), "A model for predictive measurements of advertising effectiveness", Journal of Marketing, Vol. 25 No. 6, pp. 59-62.

Lemon, K.N. and Verhoef, P.C. (2016), "Understanding customer experience throughout the customer journey”, Journal of Marketing, Vol. 80 No. 6, pp. 69-96.

Lipkin, M. (2016), "Customer experience formation in today's service landscape”, Journal of Service Management, Vol. 27 No. 5, pp. 678-703.

Lok, J. and De Rond, M. (2013), "On the plasticity of institutions: containing and restoring practice breakdowns at the Cambridge University Boat Club”, Academy of Management Journal, Vol. 56 No. 1, pp. 185-207.

Macdonald, E.K., Kleinaltenkamp, M. and Wilson, H.N. (2016), "How business customers judge solutions: solution quality and value in use”, Journal of Marketing, Vol. 80 No. 3, pp. 96-120, doi: 10.1509/jm.15.0109.

McColl-Kennedy, J.R., Vargo, S.L., Dagger, T.S., Sweeney, J.C. and Kasterenv, Y. (2012), "Health care customer value cocreation practice styles", Journal of Service Research, Vol. 15 No. 4, pp. 370-389.

McColl-Kennedy, J.R., Cheung, L. and Ferrier, E. (2015), “Co-creating service experience practices”, Journal of Service Management, Vol. 26 No. 2, pp. 249-275.

McColl-Kennedy, J.R., Zaki, M., Lemon, K.N., Urmetzer, F. and Neely, A. (2019), "Gaining customer experience insights that matter", Journal of Service Research, Vol. 22 No. 1, pp. 8-26. 
Medberg, G. and Grönroos, C. (2020), "Value-in-use and service quality: do customers see a difference?”, Journal of Service Theory and Practice, Vol. 30 Nos 4-5, pp. 507-529, doi: 10.1108/ JSTP-09-2019-0207.

Medlin, C.J. (2004), "Interaction in business relationships: a time perspective”, Industrial Marketing Management, Vol. 33 No. 3, pp. 185-193.

Mikolon, S., Kolberg, A., Haumann, T. and Wieseke, J. (2015), "The complex role of complexity: how service providers can mitigate negative effects of perceived service complexity when selling professional services", Journal of Service Research, Vol. 18 No. 4, pp. 513-528.

Miles, M.B. and Huberman, M.A. (1994), Qualitative Data Analysis: An Expanded Sourcebook, Sage, Thousand Oaks, CA.

Muller, E. and Zenker, A. (2001), "Business services as actors of knowledge transformation: the role of KIBS in regional and national innovation systems", Research Policy, Vol. 30 No. 9, pp. 1501-1516.

Norton, D.W. and Pine, B.J. (2013), "Using the customer journey to road test and refine the business model”, Strategy and Leadership, Vol. 41 No. 2, pp. 12-17.

O'Reilly, K. (2012), Ethnographic Methods, Routledge, Abingdon, Oxford.

Ostrom, A.L., Parasuraman, A., Bowen, D.E., Patrício, L. and Voss, C.A. (2015), "Service research priorities in a rapidly changing context", Journal of Service Research, Vol. 18 No. 2, pp. 127-159.

Parasuraman, A., Zeithaml, V.A. and Berry, L.L. (1988), "Servqual: a multiple-item scale for measuring consumer perceptions of service quality", Journal of Retailing, Vol. 64 No. 1, p. 12.

Patrício, L., Fisk, R., Falcão e Cunha, J.o. and Constantine, L. (2011), "Multilevel service design: from customer value constellation to service experience blueprinting", Journal of Service Research, Vol. 14 No. 2, pp. 180-200.

Rawson, A., Duncan, E. and Jones, C. (2013), "The truth about customer experience", Harvard Business Review, Vol. 91 No. 9, pp. 90-98.

Reckwitz, A. (2002), "Toward a theory of social practices: a development in culturalist theorizing", European Journal of Social Theory, Vol. 5 No. 2, pp. 243-263.

Roy, S., S, S. and Bhatia, S. (2019), "Service quality versus service experience: an empirical examination of the consequential effects in B2B services", Industrial Marketing Management, Vol. 82, pp. 52-69.

Schatzki, T.R. (1996), Social Practices: A Wittgensteinian Approach to Human Activity and the Social, Cambridge University Press, Cambridge.

Schembri, S. (2006), "Rationalizing service logic, or understanding services as experience?", Marketing Theory, Vol. 6 No. 3, pp. 381-392, doi: 10.1177/1470593106066798.

Siebert, A., Gopaldas, A., Lindridge, A. and Simões, C. (2020), “Customer experience journeys: loyalty loops versus involvement spirals", Journal of Marketing, Vol. 84 No. 4, pp. 45-66.

Storbacka, K. (2011), "A solution business model: capabilities and management practices for integrated solutions", Industrial Marketing Management, Vol. 40 No. 5, pp. 699-711.

Strauss, A. and Corbin, J. (1998), Basics of Qualitative Research Techniques, Sage publications Thousand Oaks, CA.

Taylor, S.E. (1991), "Asymmetrical effects of positive and negative events: the mobilizationminimization hypothesis", Psychological Bulletin, Vol. 110 No. 1, p. 67.

Tidström, A. and Hagberg-Andersson, А. (2012), "Critical events in time and space when cooperation turns into competition in business relationships", Industrial Marketing Management, Vol. 41 No. 2, pp. 333-343.

Toivonen, M., Tuominen, T. and Brax, S. (2007), "Innovation process interlinked with the process of service delivery - a management challenge in KIBS", Economies et Sociétés, Vol. 3, pp. 355-384.

Tommasetti, A., Troisi, O. and Vesci, M. (2017), "Measuring customer value co-creation behavior", Journal of Service Theory and Practice, Vol. 27 No. 5, pp. 930-950.

\section{Customer} service experience management 
JSTP 31,3

Tuli, K.R., Kohli, A.K. and Bharadwaj, S.G. (2007), "Rethinking customer solutions: from product bundles to relational processes", Journal of Marketing, Vol. 71 No. 3, pp. 1-17.

Van Maanen, J. (1979), "The fact of fiction in organizational ethnography", Administrative Science Quarterly, Vol. 24 No. 4, pp. 539-550.

Van Maanen, J. (2011), Tales of the Field: On Writing Ethnography, University of Chicago Press, London and Chicago.

Van Vaerenbergh, Y., Varga, D., De Keyser, A. and Orsingher, C. (2019), "The service recovery journey: conceptualization, integration, and directions for future research", Journal of Service Research, Vol. 22 No. 2, pp. 103-119.

Vargo, S.L. and Lusch, R.F. (2008), "Service-dominant logic: continuing the evolution", Journal of the Academy of Marketing Science, Vol. 36 No. 1, pp. 1-10.

Vargo, S.L. and Lusch, R.F. (2016), "Institutions and axioms: an extension and update of servicedominant logic", Journal of the Academy of Marketing Science, Vol. 44 No. 1, pp. 5-23.

Verleye, K. (2019), "Designing, writing-up and reviewing case study research: an equifinality perspective", Journal of Service Management, Vol. 30 No. 5, pp. 549-576.

Virlée, J.B., Hammedi, W. and van Riel, A.C.R. (2020), "Healthcare service users as resource integrators: investigating factors influencing the co-creation of value at individual, dyadic and systemic levels", Journal of Service Theory and Practice, Vol. 30 No. 3, pp. 277-306.

Visconti, L.M. (2010), "Ethnographic Case Study (ECS): abductive modeling of ethnography and improving the relevance in business marketing research", Industrial Marketing Management, Vol. 39 No. 1, pp. 25-39.

Voorhees, C.M., Fombelle, P.W., Gregoire, Y., Bone, S., Gustafsson, A., Sousa, R. and Walkowiak, T. (2017), "Service encounters, experiences and the customer journey: defining the field and a call to expand our lens", Journal of Business Research, Vol. 79, pp. 269-280.

Warde, A. (2005), "Consumption and theories of practice", Journal of Consumer Culture, Vol. 5 No. 2 , pp. 131-153.

Webster, F.E. and Wind, Y. (1972), "A general model for understanding organizational buying behavior”, Journal of Marketing, Vol. 36 No. 2, pp. 12-19.

Whittington, R. (2006), "Completing the practice turn in strategy research", Organization Studies, Vol. 27 No. 5, pp. 613-634.

Witell, L., Kowalkowski, C., Perks, H., Raddats, C., Schwabe, M., Benedettini, O. and Burton, J. (2020), "Characterizing customer experience management in business markets", Journal of Business Research, Vol. 116, pp. 420-430.

Woodruff, R.B. (1997), "Customer value: the next source for competitive advantage", Journal of the Academy of Marketing Science, Vol. 25 No. 2, pp. 139-153.

Yakhlef, A. (2015), "Customer experience within retail environments: an embodied, spatial approach", Marketing Theory, Vol. 15 No. 4, pp. 545-564, doi: 10.1177/1470593115569016.

Ylimäki, J. (2014), "A dynamic model of supplier-customer product development collaboration strategies", Industrial Marketing Management, Vol. 43 No. 6, pp. 996-1004.

Zeithaml, V.A., Verleye, K., Hatak, I., Koller, M. and Zauner, A. (2020), "Three decades of customer value research: paradigmatic roots and future research avenues", Journal of Service Research, Vol. 23 No. 4, pp. 409-432, doi: 10.1177/1094670520948134.

Zolkiewski, J., Story, V., Burton, J., Chan, P., Gomes, A., Hunter-Jones, P., O’Malley, L., Peters, L.D., Raddats, C. and Robinson, W. (2017), "Strategic B2B customer experience management: the importance of outcomes-based measures", Journal of Services Marketing, Vol. 31 No. 2, pp. 172-184, doi: 10.1108/JSM-10-2016-0350.

Zomerdijk, L.G. and Voss, C.A. (2010), "Service design for experience-centric services", Journal of Service Research, Vol. 13 No. 1, pp. 67-82. 


\section{Appendix 1}

This appendix lays out the narratives of service provider practices in managing CSE during critical events. Each illustration is introduced by the customer journey phase, in which the event took place and the nature and type of practice.

Illustration 1 - Train \& Co

Customer journey phase

1. Trigger and problem analysis

Practices

Ad hoc - reactive

Regular - reactive
Customer service experience management

A first meeting was held between Train \& $C_{0}$ and an HR manager (DMU) from a governmental organization. The HR manager, a potential customer, contacted Train \& Co because of challenges being faced within her organization. Train \& Co's account manager and trainer met with the HR manager at the customer's organization to discuss the current situation and the challenges faced by the HR manager personally as well as the entire organization. It seemed she had difficulty pinpointing exactly where the problem lays. This was a critical moment in the trigger and problem analysis phase because it caused doubt and insecurity for the customer.

In a dialog, the account manager and trainer asked the HR manager triggering questions to determine more about the situation. The two representatives from Train \& Co aimed to thoroughly investigate the situation and problem. After she provided Train \& Co's representatives with further information into the current situation, which seemed to lack any policy, the trainer confronted her in a polite and correct way.

If I may bring up a point? ... It already caught my attention. In the current situation, if a citizen breaks the rules three times, that person apologizes and only gets a warning, then something is not right. I can imagine that you want to give people a second chance, agreed; but in the ideal situation, your organization should implement new policies and be very consequent in following through on them. If a citizen breaks the rules, your employees should report him or her to the police. And I understand that you cannot force your employees to report someone, but you as an HR department can take that responsibility and do the reporting yourself. [Train \& Co - trainer]

Afterward, the trainer carefully advised about possible routes for improvement. The HR manager arrived at a new insight into what exactly the problem was and how Train \& Co could help.

That strikes a chord with me. I think you're right regarding that. We have been discussing several issues internally with our legal department, but your idea is novel. It often happens that our employees are directly affected by the event, and they do not want to report to the police. We always think the employee is responsible for this, one way or the other. Acting upon the event, that is the current difficulty and the point of discussion, yes... [Customer - HR manager]

First and important in such an early phase of the customer journey, Train \& Co's team was able to obtain clear insight into the customer's situation by analyzing the problem thoroughly. This worked reciprocally in the sense that the customer also obtained a clearer picture. Subsequently, by providing spontaneous constructive advice, the account manager and trainer were able to stabilize the DMU's service experience in the sense that she gained more clarity regarding the problem at hand and what could be a next step.

Illustration 2-MonITor

Customer journey phase

Practices

Ad hoc - reactive

Regular - proactive
2. Orientation and negotiation

P5. Steer toward solutions

P6. Manage the relationship strategically 
JSTP 31,3
An IT supplier of several municipalities was exploring possibilities for an IT solution. One of the candidates for supplying the IT solution was MonITor. The project leader investigated the experience of other organizations with the service provided by MonITor. This depicts how he organizes information to make his choice. All 11 respondents gave the same answer: an overall positive CSE with MonITor. Of the parties, two pointed out that they experienced a critical moment when MonITor changed personnel because one of its consultants found a job elsewhere. The consultant had already been involved during the whole trajectory and built up trust with the customer. For the project leader, this formed a critical moment in his orientation and negotiation phase since it provided him with valuable information in making his choice.

In that specific case, MonITor had acted immediately when it became known that its consultant was leaving. Employees from MonITor directly steered toward a solution in response to the unforeseen nature of the event. Moreover, the orientation and negotiation phase is commonly known at the service provider to be a phase in which it is necessary to "be on your toes" and manage the customer relationship carefully. Therefore, the consultant who was familiar with the customer arranged a "warm handshake" between his fellow consultant and the customer's team, who was pleased to be introduced to the new consultant by the previous consultant. This created trust, and the customer's team felt happy that MonITor took action toward a solution and arranged everything in an orderly manner. Although the consultant's departure altered the CSE, MonITor restored it by providing the customer with the best possible solution while simultaneously managing the relationship strategically, which further boosted the CSE.

Illustration $3-$ Train \& Co

Customer journey phase

2. Orientation and negotiation

Practices

Regular - reactive

P1. Provide constructive advice

P3. Analyze the problem thoroughly

P7. Take decisive action

P8. Manage expectations

The L\&D manager from the customer's organization pointed out that she and her colleagues had created insight into the personal development training needs of its employees. The two departments that were scheduled to engage in training had different needs. The employees of one department wanted a maximum of one day of training, and the other wanted only half a day. During the meeting with Train \& Co's account manager and trainer, the L\&D manager pointed out an important hurdle. The employees seemed to be training averse. This situation clearly showed that the L\&D manager faced the problems herself, and this critical event prevented Train \& Co from delivering clear CSE in the customer's orientation and negotiation phase.

As it is important to be clear from the start, the account manager first took decisive action by pushing back on the needs of the employees during the meeting. Subsequently, he asked questions to tap further into the customer's situation. The conversation is iteratively reproduced below, with the account manager and trainer aiming to understand the problem in depth while taking decisive action. They managed the customer's expectations and communicated what was feasible and realistic.

Only half a day?! That's very short, too brief and something I would not recommend. It's more like a workshop instead of a real training. But tell me, what exactly is the reason they only want a maximum of one day and half a day of training? [Train \& $\mathrm{Co}$-account manager]

The L\&D manager pointed out the following:

I think it has to do a lot with previous experience. I get your point, and it does not mean that it counts for every single employee, but it is what we found on average. I know this organization quite well, and I know that more than one day of training, no.... It sounds cliché but that is impossible with work. [Customer - L\&D manager]

The trainer joined the discussion and gave constructive feedback together with realistic advice: 
Look, in one day you can schedule quite a complete training. I'm able to discuss general theories and concepts. However, in half a day, that's impossible. Half a day is more like a workshop to give people an idea what the training is about. If you choose half a day, I advise incorporating another half a day later to explain the methodology and give some practical exercises to better embed the knowledge in people's minds and bridge the theory to practice. This is simply not possible in half a day. And of course, if you insist on your initial ideas, be my guest, but I strongly discourage it because it is not effective. [Train \& Co - trainer]

Wrapping up their discussion, the L\&D manager seemed convinced about the point the account manager and trainer had made. She took their ideas into account, showed more confidence, and pointed out that the next hurdle was to convince other internal stakeholders who had control and mandate over the budget. In other words, she acted as an advocate for Train \& Co within her own organization. The account manager and trainer provided constructive advice on proposal planning. While it was still necessary to overcome other internal challenges, the service experience of the L\&D manager was more stable. Moreover, she was relieved to receive support from the account manager and trainer of Train \& $\mathrm{Co}$.

I get your point, and my proposition is that I will get in touch with the manager of both departments to point exactly out what you mentioned. So I'm going to check what they are capable of. You know, my opinion is, if you already book half a day, it makes absolutely sense to just book the whole day.... One of the managers has a great affinity with such topics, so I do not worry about her. To convince the other is a bigger challenge, but we will see. I'll contact them next week, and I'll come back to you ASAP. As you suggested, you can then send me a planning proposal. [Customer - L\&D manager]

Illustration $4-$ Train \& Co

Customer journey phase

Practices

Ad hoc - reactive

Regular - reactive

Regular - proactive

\section{Orientation and negotiation}

P6. Manage the relationship strategically

P7. Take decisive action

P2. Tailor the value promise

P9. Empathize with the customer

The customer's HR manager (DMU) of a health organization is responsible for the development of their employees on a strategic, tactical and operational level. While searching for suppliers, she selected two service providers to discuss further possibilities for providing a wide range of personal development training. Because she had already collated much information and, based on this, conducted a problem analysis herself, she seemed to be clear about what she wanted to ask Train \& Co. This is an important moment in the customer's journey. The HR manager was on the verge of making a decision for a service provider, which made it a "moment of truth" for Train \& $\mathrm{Co}$. The service experience of the HR manager was fragile at this moment in the sense that she could either be disappointed or satisfied with Train \& Co's offering.

Michael (Train \& Co's account manager) was overwhelmed by everything she asked for. In his opinion, the needs were very scattered, which negatively influence the effectiveness of trainings. Additionally, the scope of the discipline was too broad. Michael gave pushback on this and advised starting small with a clear target group. He proposed an alternative offering that would probably better suit the customer's organization.

The HR manager was pleasantly surprised with the account manager's advice.

I remember when Michael told me, "If you want all of this, you should look for another service provider. I'm not going to commit myself to this." I really appreciated the honest feedback, and I'm happy he gave me pushback. My plans were too ambitious. Michael sincerely advocated for what was good for us and did not act from a commercial point of view. [Customer - HR manager]

By empathizing with the customer's situation, the account manager was able to understand its deeper needs. Acting decisively through giving pushback on the initial needs expressed by the HR manager resulted in a pleasantly surprised customer. The account manager carefully managed their relationship through his customer-centric approach and tailored its possible value offering in a proactive manner. 
JSTP 31,3
Illustration 5-MonITor

Customer journey phase

3. Choice and purchase phase

Practices

Ad hoc - reactive

Regular - reactive
P6. Manage the relationship strategically P5. Steer toward solutions

P9. Empathize with the customer

The potential customer was about to make a choice for MonITor's solution. John, the account manager, was the fixed contact person for the customer. He had had intensive contact in the previous months, providing the customer with information and building up a relationship. John arranged a kick-off meeting with several stakeholders (interim manager [DMU], project leader and several IT architects) at the customer's offices. This was a critical event because John could not be present at the kick-off meeting for this large-scale project. Thus, the customer's service experience was altered by the service provider.

Since John was on summer holiday, Bob (director of MonITor) temporarily replaced him at the meeting. Bob's goal was to show MonITor's commitment toward the customer's team, and the priority MonITor was giving the project. However, in an in-depth interview with the project leader - a couple of weeks after the kick-off meeting - he pointed out that he was surprised by the action MonITor took, replacing John with Bob in John's absence. He had an uncanny and skeptical feeling.

You know, Bob showed up. That felt wrong to me. John should have been here, not Bob. He introduced himself as the director of MonITor. Even though I know they are not a player like Microsoft. . . With everything he said, I wondered, would John have said that? That's really strange. Sometimes during the presentation, I thought "Yes, it's Bob". . We knew John already, he knows his topic, and we had already built a relationship with him. And if Bob is going to attend such meetings more often, should not he be at least acquainted with the skills and knowledge John has? As a customer, it is part of your choosing process, and such a relatively minor factor can determine whether to sign a contract or not, well that could count... John is going to tell us what's good for us, and in that respect, there is no room for someone else. I'm not sure whether my colleagues felt the same, but in my role of project leader, it's of the utmost importance to monitor every decision in terms of budget, planning, and scope. Especially who are you talking to and what their roles are.... It is very important, and it depends on the phase that we are in. During our selection, the account manager is very important. Also during the contract phase. But at this moment, during the implementation phase, the consultant is more important. [Customer - project leader]

MonITor clearly attempted to maintain a stable CSE by showing commitment through personnel replacement when needed. In that sense, they acted in a solution-oriented manner. Employees from MonITor emphasized that the kick-off meeting for a large project is of the utmost importance for the customer. They carefully managed their relationship. Despite all their useful actions and efforts, uncoordinated management in terms of lack of internal coordination by the account manager showed how CSE can flip around. It caused an unforeseen change in personnel for the customer. Therefore, it was necessary for MonITor to stabilize and repair the project leader's service experience again. This illustration depicts that CSE management is a continuous iterative process involving managing internal and external stakeholders.

Illustration 6-MonITor

Customer journey phase

Practices

Ad hoc - reactive

Regular - proactive
3. Choice and purchase phase

P4. Solve problems ad hoc P5. Steer toward solutions P8. Manage expectations 
A critical event occurred because of a lack of clarity in agreements between the customer and MonITor. It caused friction, resulting in an unsettled CSE. During a meeting in which a customer was about to sign a contract with MonITor, the project leader pointed out that he did not know about the agreements that were made with his colleagues and MonITor. This shows his active role, in terms of project governance, in effective working relationships. He asked, surprisingly,

Which agreements did you make with our developer? [Customer - project leader].

The representative of MonITor acted on this and responded immediately,

Yesterday, I got an email from your developer with several questions based on the answers I gave him in earlier email correspondence. We agreed that I would contact our development department, and depending on how soon I got a response, I would follow up with you. Based on this, I promise to send you the formal agreement before the end of next week. [MonITor - director]

The project leader seemed to be content with the outcome:

Perfect. That's sufficient for me because then I can set up and arrange internal issues. Super. Thanks very much, and we will keep in touch then. [Customer - project leader]

First, the critical event arose because of uncoordinated management by MonITor. As a response, the director of MonITor took immediate action and aligned the customer's internal departments with its own service desk. He promised a quick follow-up, which safeguarded the service experience of the customer's project leader. By having solved the problems ad hoc and still being solution-oriented, the service provider carefully managed the customer's expectations and secured its service experience.

Illustration 7-MonITor

Customer journey phase

4. Implementation and usage

Practices

Ad hoc - reactive

Regular - reactive

P10. Stabilize the situation

P9. Empathize with the customer

In the current situation, the customer made use of MonITor's offering, which concerned an IT application. The critical event arose during the usage phase, when the customer's IT manager (DMU) pointed out that MonITor lacked proactive communication in terms of information provision in cases of breakdowns or about possibilities on offer. While the situation was critical, it shows that MonITor played an active role in "colearning" by providing feedback to the service provider.

I'm not satisfied with the communication between us so far. Communication is of vital importance. So please, communicate. The more, the better! [Customer - IT manager]

MonITor acted too late the first time a minor breakdown occurred. With the second breakdown, the customer's team got in touch first. MonITor's account manager contacted the internal support desk to fix the problem. This provided the customer with a solution for the current case. However, in future collaboration, the IT manager does not expect "one-off solutions" but continuous, more proactive, communication from MonITor. He remains slightly skeptical.

This illustration shows that the service provider repaired the situation by acting according to the customer's wishes and aligning internal departments. Empathizing with the customer's situation is of crucial importance. Even though the customer was provided with a solution and the CSE was stabilized, this critical event shows the fragility of CSE. It can be easily unbalanced, and it takes effort to restore the balance. The illustration also demonstrates that customers' future expectations might change.

Illustration 8-MonITor

Customer journey phase

4. Implementation and usage

Practices

Ad hoc - reactive

P4. Solve problems ad hoc

Ad hoc-proactive

P7. Take decisive action

Regular - reactive

P5. Steer toward solutions

P9. Empathize with the customer 
JSTP 31,3

The customer has been making use of MonITor's offering for a couple of months. During an update meeting, the customer's head of back office provided feedback by pointing out that when breakdowns occur, the current system does not provide insight into what is going wrong. This is critical for the customer because it directly impacts its internal processes. Despite the fact that the error was quickly fixed, the customer was looking for stability in his back-office processes, which currently could be improved. This formed a critical event that affected both the CSE and the relationship with MonITor.

While demonstrating what was going on, the head of back office pointed out the following:

See... I am missing thresholds over here. On this dashboard, I need more information that thoroughly shows me what's going on. This is too superficial. [Customer - head of back office]

MonITor's account manager first showed an understanding of the customer's situation. He promised that MonITor's support desk would get in touch, and they collaboratively sought possibilities in the system to create additional insight for the customer. The account manager then explored possible solutions at the customer's organization and proposed installing dashboards on walls in the back office. He stated the following:

I do not see any screens showing the dashboards. This is absolutely necessary because it shows you what's happening and what you need to do. [MonITor - account manager]

The customer's representative understood the remark made by MonITor's account manager. He looked happy and satisfied with the outcome of the meeting and showed understanding:

I fully agree with what you just said. It only comes to life if there are screens present in my department. Everybody should be able to see what's happening. [Customer - head of back office]

Clearly, the account manager's action showed that solving problems ad hoc is important for temporarily stabilizing the CSE. Acting in a solution-oriented manner by presenting immediate solutions helps the customer's team solve its own problems, which directly improves the CSE. Moreover, by empathizing with the customer and showing understanding while at the same time being decisive, the customer seems to gain confidence and trust in the service provider.

Illustration $9-$ Train \& Co

Customer journey phase

Practices

Ad hoc - reactive

Regular - reactive

Ad hoc - proactive
5. Evaluation and follow-up

P1. Provide constructive advice P3. Analyze the problem thoroughly P5. Steer toward solutions $\mathrm{P} 1$. Provide constructive advice

Train \& Co just finished a long-term project with different types of training courses at one customer. Several groups of employees with different roles, responsibilities and backgrounds attended the training sessions. Although the customer's HR department is satisfied with the project, it faces challenges with safeguarding the knowledge and skills the employees learned within the organization and using them in daily practice. This moment in time is important for both parties. The customer is facing challenges. Its service experience is affected when the provider is not able to ensure retention within the organization, despite the fact that the actual training sessions are complete. This phase is a key moment for the service provider because they can excel in facilitating the customer with a solid CSE or even offering a follow-up project.

The account manager scheduled a meeting with five representatives of the customer's HR department. He brought along his colleague who is a trainer. The agenda for the meeting focused on how the organization can safeguard what the employees learned from the training sessions. The account manager and the trainer prepared well for the meeting. They had already exchanged a couple of ideas. During the meeting, it was clear that the account manager and the trainer were in control. They structured the meeting and began by asking questions about the current situation and requesting more background information about the problems the organization was facing, followed by initiatives for 
improvement. They suggested, for example, introducing "ten-minute talks" with the trainer in the months after the training courses to embed the skills in the employees' own work. Another example was to set up a "coach-the-coach" trajectory in which the managers are coached by the account manager and trainer. This would help managers coach their own employees and encourage them to use the skills and knowledge they learned from the training.

It is clear that the whole HR team was happy with the results. Expressions such as "eye-opening" were regularly expressed, showing that expectations were exceeded. All representatives thanked the account manager and trainer for their help. The highest HR manager in the class complimented with them and said that she will try to convince the board (DMU) that both the training sessions and the safeguarding process deserve C-level priority. This act of internally advocating for Train \& Co's services clearly depicts her active role in the service delivery process.

Directly after the meeting while standing in front of the customer's office, the account manager and trainer took a moment to share views on the meetings. Full of enthusiasm, the account manager told the trainer, "I should bring you with me more often!". The trainer nodded affirmatively, and they shook hands.

The account manager and trainer played a crucial role in exceeding expectations and strongly managing the CSE. They analyzed the problem thoroughly by conducting a careful root-cause analysis of the customer's situation. During the entire meeting, the account manager and trainer provided constructive advice in response to customers' questions. The account manager and trainer steered the meeting toward solutions and proposed concrete and novel solutions, and the customer was positively surprised and seemed hopeful that they could overcome their challenges. In some instances, the account manager and trainer proactively provided advice to the customer, which amounted to a surpassed CSE.

\title{
Appendix 2
}

Supplementary table is available online for this article

\begin{abstract}
About the authors
Yasin Sahhar is a $\mathrm{PhD}$ researcher at the research group entrepreneurship and technology management at the University of Twente, The Netherlands, and a consultant in strategic marketing at The Next Organization. His research interest lies in value creation and value experience from a service logic perspective. In his consultancy work, he helps industry leaders with strategy and marketing-related challenges. Yasin Sahhar is the corresponding author and can be contacted at: y.sahhar@utwente.nl

Raymond Loohuis works as a senior lecturer for the research group entrepreneurship and technology management at the University of Twente, The Netherlands. His research focuses on the emergence of servitization as a business strategy and smart industrial technology adoption and value creation in small- and medium-sized manufacturing firms.

Jörg Henseler is a professor and holds the chair of product-market relations at the department of design, production and management at the University of Twente, the Netherlands. He is also a visiting professor at Nova Information Management School, Universidade Nova de Lisboa, Portugal. His research bridges behavioral and design science and focuses on the management of products, services and brands. Web of Science/Clarivate repeatedly distinguished him as a highly cited researcher.
\end{abstract}

For instructions on how to order reprints of this article, please visit our website:

www.emeraldgrouppublishing.com/licensing/reprints.htm

Or contact us for further details: permissions@emeraldinsight.com 